
River Ice Control with Booms

US Army Corps of Engineers ${ }_{\circledast}$

Engineer Research and Development Center

Lianwu Liu and Hung Tao Shen

August 2000 
Abstract: In this study a two-dimensional numerical model for simulating ice transport and accumulation in the vicinity of river ice booms is developed. The model considers the dynamics of surface ice transport in the river, coupled with the hydrodynamics of the flow. The water flow inside the moving surface ice and the ice accumulation is included in the hydrodynamics. The Lagrangian discrete-parcel method with smoothed particle hydrodynamics is used to simulate the ice dynamics and a finite-element method is used to solve the hydrodynamic equations. Ice entrainment at the boom or the leading edge and underside of the ice accumulation, as well as the limiting boom load for ice retention, are considered. The model is verified with analytical solutions for idealized ice jams in a rectangular channel, and calibrated to an ice jam that progressed up the lower Missouri River during January 1977. The model is then used to assess the feasibility of ice booms on the lower Missouri River. The results show that conventional ice booms may not be effective for typical flow conditions in the lower Missouri River, unless the water level at the MissouriMississippi River confluence is high and the water discharge is low.

\footnotetext{
How to get copies of CRREL technical publications: tion Center:

DTIC-BR SUITE 0944

8725 JOHN J KINGMAN RD

FT BELVOIR VA 22060-6218

Telephone (800) 225-3842

E-mail help@dtic.mil msorders@dtic.mil

WWW http://www.dtic.mil/

All others may order reports through the National Technical Information Service:

NTIS

5285 PORT ROYAL RD

SPRINGFIELD VA 22161

Telephone (703) 487-4650

(703) 487-4639 (TDD for the hearing-impaired)

E-mail_orders@ntis.fedworld.gov

WWW http://www.ntis.gov/index.html

A complete list of all CRREL technical publications is available from USACRREL (CEERD-IM-HL)

72 LYME RD

HANOVER NH 03755-1290

Telephone (603) 646-4338

E-mail_erhoff@crrel.usace.army.mil
}

Department of Defense personnel and contractors may order reports through the Defense Technical Informa-

For information on all aspects of the Cold Regions Research and Engineering Laboratory, visit our World Wide Web site:

http://www.crrel.usace.army.mil 


\section{Technical Report ERDC/CRREL TR-00-10}

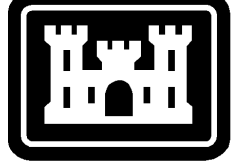

US Army Corps of Engineers ${ }_{\circledast}$ Cold Regions Research \& Engineering Laboratory

\section{Numerical Simulation of River Ice Control with Booms}

Lianwu Liu and Hung Tao Shen 


\section{PREFACE}

This report was prepared by Lianwu Liu, Research Assistant, and Hung Tao Shen, Professor, Department of Civil and Environmental Engineering, Clarkson University. This study was supported by the U.S. Army Engineer Research and Development Center, Cold Regions Research and Engineering Laboratory, through Contract No. DACA89-94-K-0017.

The writers acknowledge the assistance and valuable input of Andrew M. Tuthill. Technical review for this report was provided by Dr. Jean-Claude Tatinclaux and Andrew M. Tuthill, both of CRREL's Ice Engineering Research Division.

The contents of this report are not to be used for advertising or promotional purposes. Citation of brand names does not constitute an official endorsement or approval of the use of such commercial products. 


\section{CONTENTS}

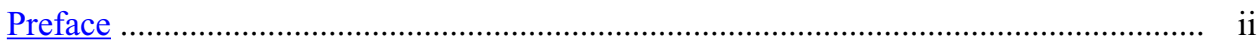

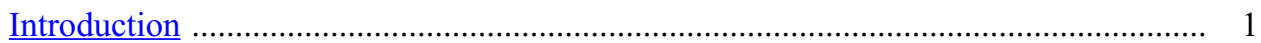

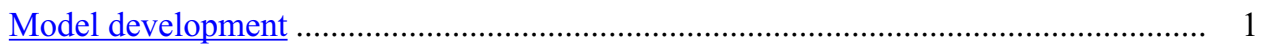

Hydrodynamic model ................................................................................. 3

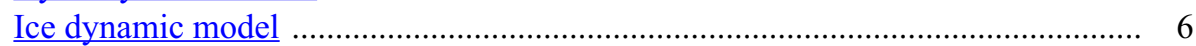

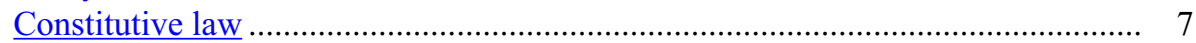

Initial and boundary conditions ....................................................................... 8

Limiting conditions for ice accumulation behind the boom ................................... 8

Ice load on the boom ...................................................................................... 9

Model verification and calibration ............................................................................. 10

Verification of the hydrodynamic model with a uniform ice cover ....................... 10

Analytical solutions for river ice jams .............................................................. 10

Open water calibration for Missouri River ......................................................... 13

Simulation of the January 1977 Missouri River ice jam ........................................ 14

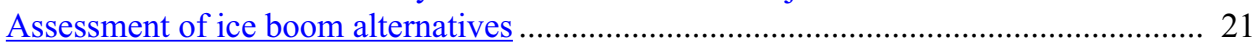

$100 \%$ effective ice booms normal to flow direction ................................................. 21

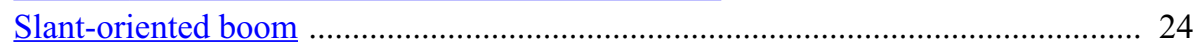

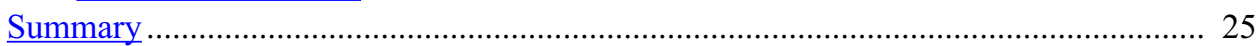

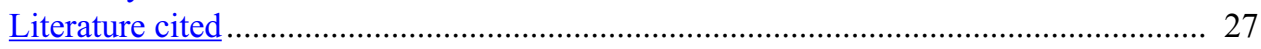

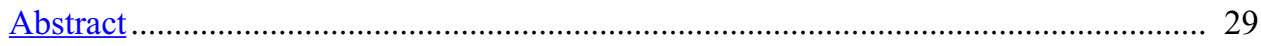

\section{ILLUSTRATIONS}

Figure

1. Middle Mississippi and lower Missouri Rivers ................................................. 2

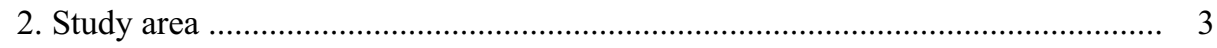

3. Definition sketch ................................................................................ 4

4. Definition sketch for grounded ice accumulation ............................................... 4

5. Interaction of a differential element of ice rubble with the boom ...................... 10

6. Comparison of water surface profiles .............................................................. 11

7. Comparison of simulated jam profiles and the analytical solution for the zero bank friction case ............................................................................... 12

8. Comparison of simulated jam profiles with the analytical solution for the

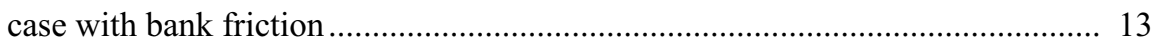

9. Ice thickness distributions ............................................................................. 14

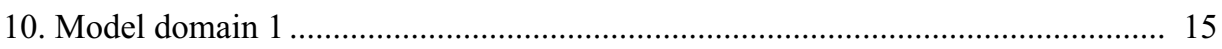

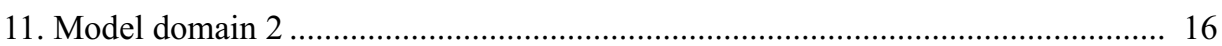


12. Comparison of ice-free water surface profiles

13. Simulated ice thickness distribution behind the boom at RM $16 \ldots \ldots \ldots \ldots \ldots \ldots \ldots \ldots \ldots . .19$

14. Simulated ice thickness distribution behind the boom at RM 8.2 ....................... 20

15. Simulated ice thickness distribution behind the boom at RM 16 ........................ 22

16. Simulated ice thickness distribution behind the boom at RM 8.2 ....................... 23

17. Water surface profiles ................................................................................ 24

18. Simulated load distribution on the boom ........................................................... 25

19. Bed elevation in the vicinity of the slant-oriented boom at RM 16 .................... 26

\section{TABLES}

Table

1. Parameters used in the ice dynamic simulation .......................................... 11

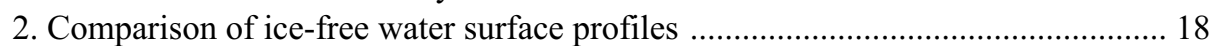

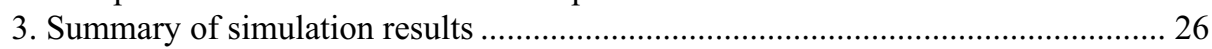




\section{NOMENCLATURE}

$\alpha_{h} \quad$ Fraction of water flow depth affected by the bed friction

$\varepsilon_{i j} \quad$ Generalized eddy viscosity coefficients

$\varepsilon_{\mathrm{ij}} \quad$ Strain rate tensor

$\phi \quad$ Internal friction angle of ice

$\phi_{\mathrm{B}} \quad$ Boundary friction angle

$\gamma^{2} \quad$ Wind drag coefficient

$\eta \quad$ Water surface elevation

$\eta^{\prime} \quad$ Elevation of the undersurface of the ice layer

$\lambda \quad$ Seepage flow coefficient

$\mu \quad$ Nonlinear viscosity coefficient in constitutive law

$\theta_{\mathrm{a}} \quad$ Angle between the wind direction and the $x$-axis

$\rho \quad$ Water density

$\rho_{\mathrm{a}} \quad$ Air density

$\rho_{\mathrm{i}} \quad$ Ice density

$\sigma \quad$ Internal ice stress

$\tau_{\mathrm{ax}}, \tau_{\mathrm{ay}}$ Components of wind drag on ice

$\overrightarrow{\tau_{\mathrm{b}}} \quad$ Shear stresses on the riverbed

$\tau_{\mathrm{ix}}, \tau_{\mathrm{iy}} \quad$ Components of seepage flow water drag on ice

$\overrightarrow{\tau_{\mathrm{s}}} \quad$ Shear stresses at the ice-water or air-water interface

$\tau_{\mathrm{wx}}, \tau_{\mathrm{wy}}$ Components of lower-layer-flow water drag on ice

$A_{\mathrm{b}} \quad$ Flow area affected by the bed resistance

$A_{\mathrm{i}} \quad$ Flow area affected by the ice resistance

$c_{\mathrm{a}} \quad$ Wind on ice drag coefficient

$c_{\mathrm{f}} \quad$ Bed resistance coefficient

$c_{\mathrm{W}} \quad$ Water on ice drag coefficient

$\overrightarrow{F_{\mathrm{a}}} \quad$ Wind drag on ice

$F_{\mathrm{c}} \quad$ Ice cohesive force

$F_{\mathrm{f}} \quad$ Frictional force between ice and the solid boundary

$F_{\mathrm{N}} \quad$ Normal ice force against the solid boundary

$\overrightarrow{F_{\mathrm{w}}} \quad$ Water drag on ice

$G \quad$ Gravitational force attributable to water surface slope

$G_{\mathrm{x}}, G_{\mathrm{y}}$ Components of gravitational force attributable to water surface slope

$h \quad$ Water depth below the reference level

$H \quad$ Total water depth

$H^{\prime} \quad$ Water depth beneath the ice layer

$H_{\mathrm{u}} \quad$ Net water depth in the ice layer

$k \quad$ Dimensionless empirical coefficient for seepage flow formula

$K \quad$ Hydraulic conveyance

$K_{\mathrm{i}} \quad$ Conveyance of flow carried by ice

$K_{1} \quad$ Conveyance of the lower water layer

$K_{\mathrm{S}} \quad$ Conveyance of seepage flow

$K_{\mathrm{t}} \quad$ Total conveyance of flow

$K_{\mathrm{u}} \quad$ Total conveyance of flow in the upper ice layer

$M_{\mathrm{i}} \quad$ Ice mass per unit area

$M_{\mathrm{S}} \quad$ Average surface area per volume of ice

$n_{\mathrm{b}} \quad$ Manning's coefficient of river bed

$n_{\mathrm{i}} \quad$ Manning's coefficient of ice

$N \quad$ Ice concentration

$p \quad$ Ice porosity

$P \quad$ Internal ice pressure term in the constitutive law 


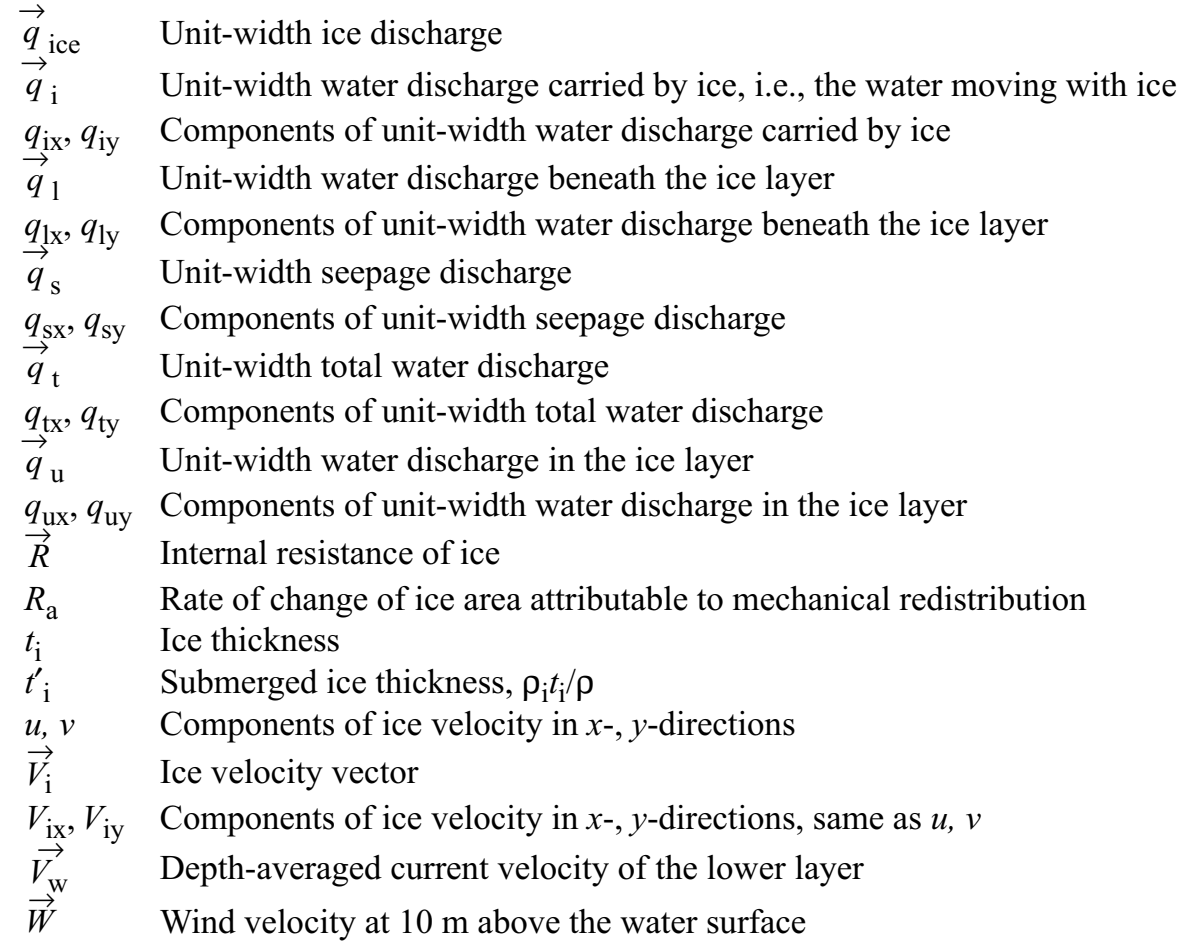




\title{
Numerical Simulation of River Ice Control with Booms
}

\author{
LIANU LIU AND HUNG TAO SHEN
}

\section{INTRODUCTION}

The middle Mississippi River, from its confluence with the Missouri River to where it joins the Ohio River at Cairo, Illinois (Fig. 1), is a vital navigation route. During the winter months, however, floating ice can accumulate and block shipping from that section of the river. Ice sources are the Missouri River and the middle Mississippi itself. In addition to suspending navigation, financial consequences include ice damage to river training structures when the ice releases. Severe ice conditions occur roughly one winter in seven, with 1989, 1979, 1977, 1970, 1962, 1958, 1951, and 1936 standing out in the recent historical record. The worst of these cases occurred in January 1977, when an ice jam delayed barges at Cairo for 27 days at an estimated cost of \$19 million. The 1977 event also caused \$1.5 million in damage to river regulating structures below Commence, Missouri, when the ice jam released. Even during winters without major ice events, delays to navigation and operational difficulties resulting from ice are common problems. Tuthill and Mamone (1998) provide a detailed description of the middle Mississippi ice problems and control alternatives.

The Missouri River, which is officially closed in winter for navigation, and is uncontrolled for $1250 \mathrm{~km}$ upstream from its confluence with the Mississippi River, generates large amounts of ice. Records from the Missouri River Division (MRD) of the U.S. Army Corps of Engineers report that ice jams have formed at RM* 6. The Lewis Bridge at RM 8 may aid the initial ice arching (Fig. 2). The backwater from the Mississippi confluence may also contribute to jamming in this reach by reducing water surface slope and velocity. Once

*River mile. initiated, this cover presents a barrier to frazil and ice floes arriving from upstream. Ice will either accumulate at the leading edge of the cover or, if the water velocity is sufficiently high, it will be carried under the leading edge to be deposited under the ice cover. If the water velocity is too high, ice will be swept downstream and the ice cover will not progress. Tuthill and Mamone (1998) showed that installing an ice retention structure in the lower Missouri River to reduce the quantity of ice reaching the middle Mississippi would also have the benefit of reducing the ice jam problems in that stretch of the river and at the Missouri-Mississippi confluence. Ice control schemes, consisting of floating booms, pier structures, and artificial islands, have been used successfully on the St. Lawrence River (Tuthill 1995). For the lower Missouri River, the average slope is on the order of $1.7 \times 10^{-4}$. The average water velocity is high, with a range of 0.75 to $1.8 \mathrm{~m} / \mathrm{s}$. Using a onedimensional, steady-state model of ice cover progression, Tuthill and Mamone (1998) found that, at low Missouri River flows, the water velocity approaches $0.7 \mathrm{~m} / \mathrm{s}$ between RM 15 and 20, and that floating booms might be successful, so a detailed study of the boom locations was needed. This report details a twodimensional dynamic simulation model of river ice that was developed to assess the feasibility of ice control on the lower Missouri River using booms.

\section{MODEL DEVELOPMENT}

Theories on ice jams that are based on the static equilibrium of floating accumulations of granular ice are well developed (Pariset and Hausser 1961, Uzuner and Kennedy 1976, Beltaos 1983). Static ice jam theories, which neglected the dynamic effect of the ice 


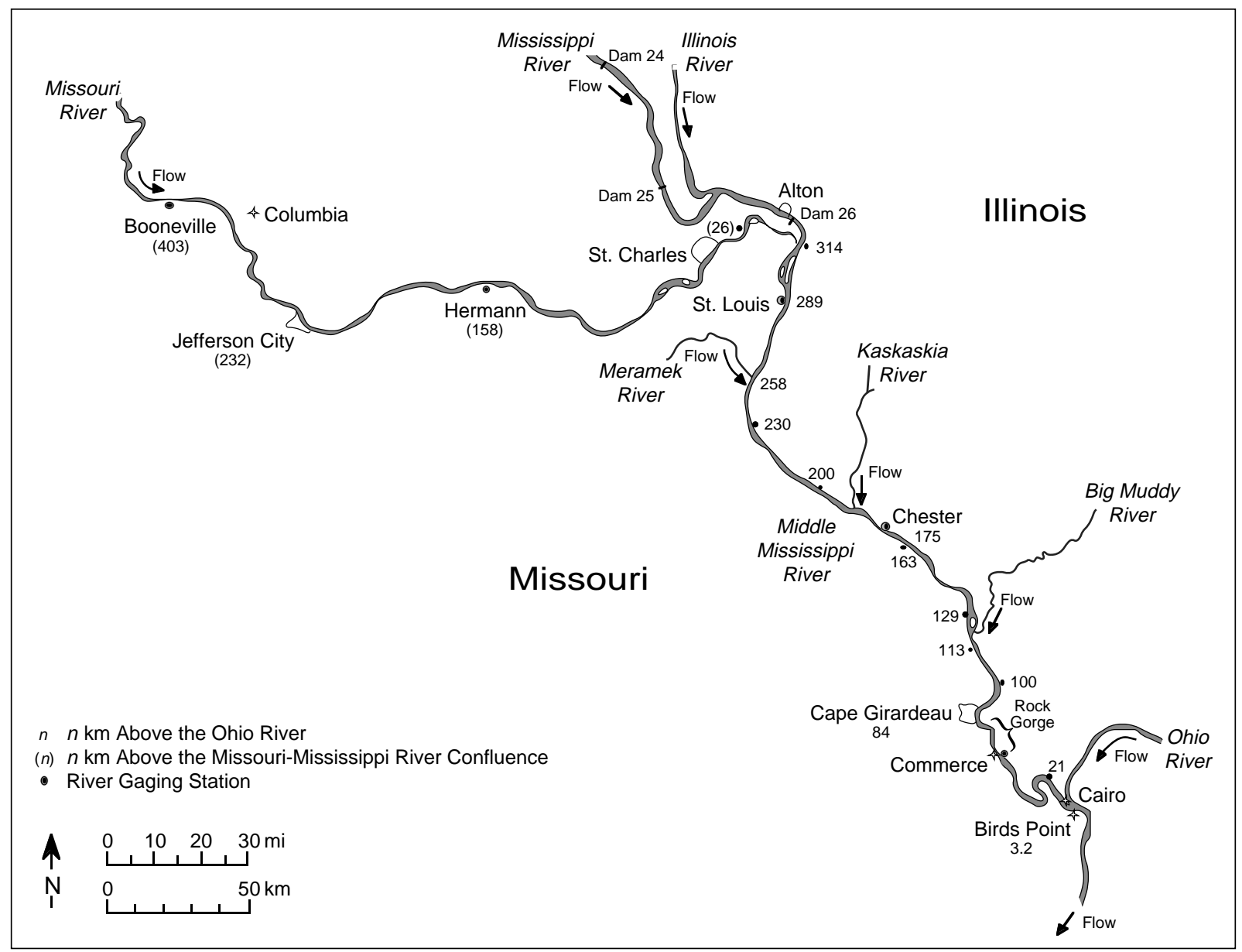

Figure 1. Middle Mississippi and lower Missouri Rivers. (From Tuthill and Mamone 1998.)

motion, were derived on the basis of one-dimensional formulations. These theories have been used successfully to determine ice jam thickness along a river. Flato and Gerard (1986) and Beltaos (1993b) developed one-dimensional numerical models for computing the configuration of static ice jams. Beltaos' model is also capable of simulating grounded jams. Since the dynamics of the ice movement and flow were not considered, the static ice jam theories cannot explain the formation of ice jams. They also cannot determine whether, when, and where a jam will form. Moreover, the momentum effects of ice and water flows on the ice jam evolution and thickness were not accounted for in the static ice jam theories.

Shen et al. (1990) developed an analytical framework for the dynamic transport of river ice and ice jam formation and evolution. Lal and Shen (1991) developed a numerical model for simulating dynamic ice transport and ice jam evolution in river channels and showed the importance of the inertia effect on ice jam configuration. They also showed that the water wave speed is not affected by the ice conditions, and that the speed of the stress wave in the ice layer is not related to the speed of water waves. As a result of this independence, water and ice flow equations need not be solved simultaneously. Moreover, the speed of characteristic waves of the water and ice equations can be significantly different. The temporal and spatial discretizations in the numerical solutions have to be treated with care. More recently, Zufelt and Ettema (1997) used a simplified one-dimensional formulation to study the dynamic effect on ice jam thickness profiles in prismatic channels. They used the Mohr-Coulomb law for static passive granular accumulation to describe the internal ice stress.

One-dimensional models have limited applicability, as river ice transport and ice jam evolution are twodimensional phenomena attributable to the existence of bank friction and nonuniform water currents. Shen et al. (1993) developed a two-dimensional dynamic river ice transport model, which was successfully used to study the dynamics of ice transport and jamming in the upper Niagara River (Su et al. 1997, Lu et al. 1999). It was also modified and applied to study the transport of 


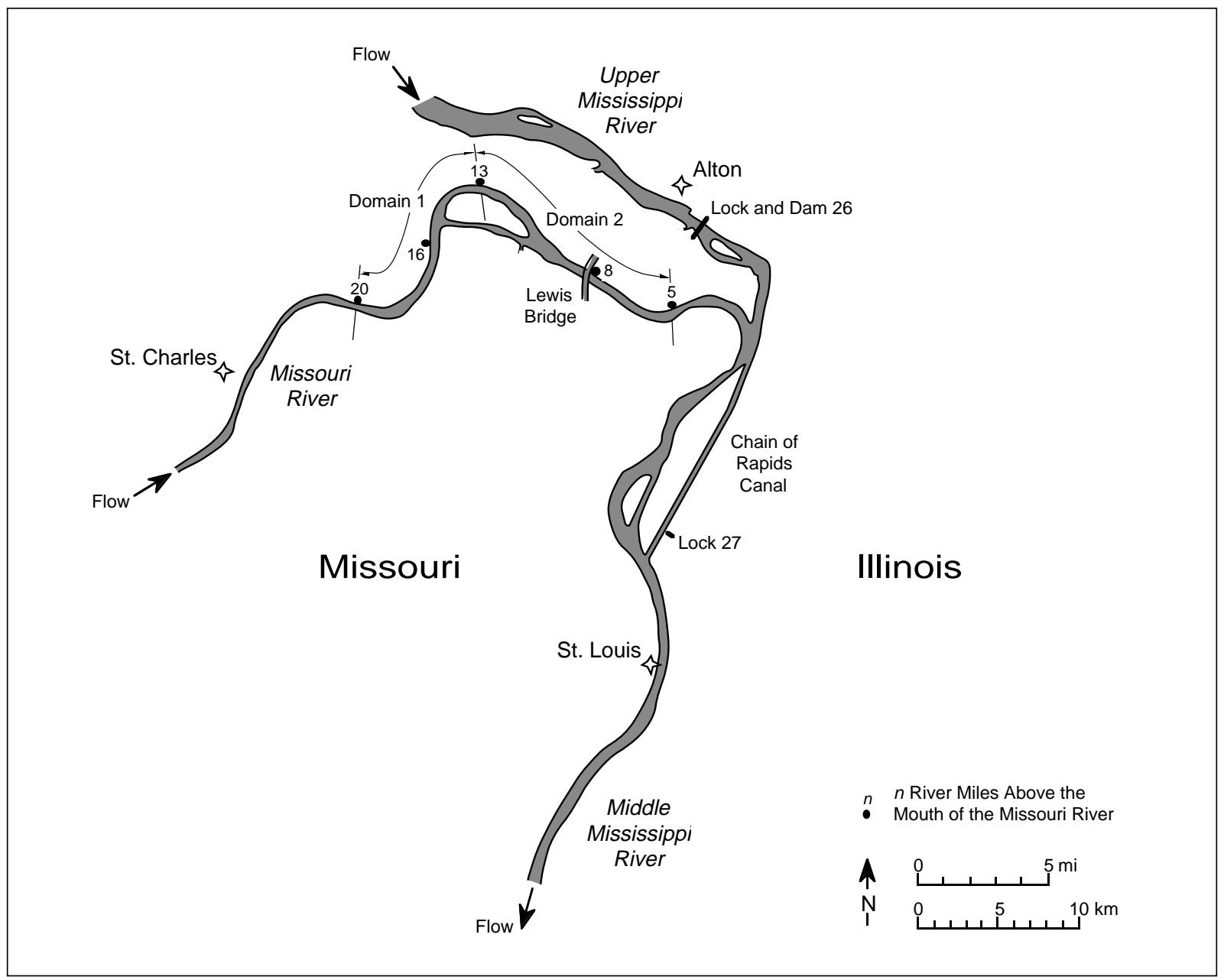

Figure 2. Study area.

lake ice over the Lake Erie-Niagara River Ice Boom (Shen et al. 1997). Su (1997) further refined the model to include the water flow in the surface ice layer, so that grounded ice accumulations could be more accurately modeled.

In this report, the models of Shen et al. (1997) and $\mathrm{Su}$ (1997) are refined to simulate the dynamic ice transport and ice jam processes. This study applies the model to assess the feasibility of ice control on the lower Missouri River using floating booms. The model equations and numerical methods are described in the following sections.

\section{Hydrodynamic model}

By considering the flow in a river with an upper surface ice layer and a lower water layer, as shown in Figure 3, the total water and ice mass conservation equation for the case with a floating ice layer can be written as

$$
\begin{gathered}
\frac{\partial\left[\rho H^{\prime}+\rho t_{\mathrm{i}}^{\prime}(1-N)+\rho_{\mathrm{i}} t_{\mathrm{i}} N\right]}{\partial t}+ \\
\nabla \cdot\left(\rho \vec{q}_{1}+\rho \vec{q}_{\mathrm{u}}+\rho_{\mathrm{i}} \vec{q}_{\text {ice }}\right)=0
\end{gathered}
$$

in which

$$
\begin{aligned}
H^{\prime} & =h+\eta^{\prime}=\text { water depth beneath the ice layer } \\
h & =\text { water depth below the reference level } \\
\eta^{\prime} & =\text { elevation of the undersurface of ice } \\
t_{\mathrm{i}} & =\text { ice layer thickness } \\
t_{\mathrm{i}}^{\prime}=\rho_{\mathrm{i}} t_{\mathrm{i}} / \rho & =\text { submerged ice thickness } \\
\rho & =\text { water density } \\
\rho_{\mathrm{i}} & =\text { ice density } \\
N & =\text { ice concentration, i.e., the volumetric }
\end{aligned}
$$




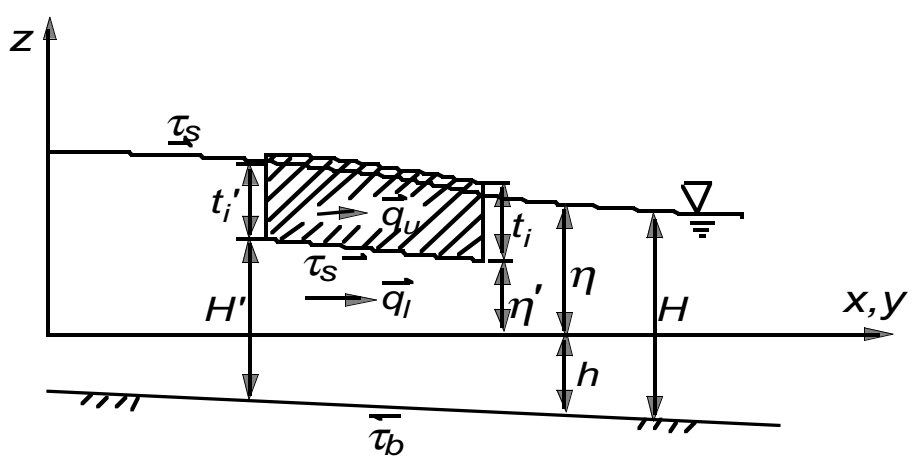

Figure 3. Definition sketch.

$$
\begin{aligned}
& \quad \begin{array}{l}
\text { fraction of the solid phase in the ice-water } \\
\text { mixture }
\end{array} \\
& \vec{q}_{1}=\text { unit-width water discharge beneath the } \\
& \vec{q}_{\mathrm{u}}=\text { ice layer } \\
& \vec{q}_{\text {ice }}=\vec{V}_{\mathrm{i}} N t_{\mathrm{i}}=\text { unit-width ice discharge } \\
& \vec{V}_{\mathrm{i}}=\text { ice velocity. }
\end{aligned}
$$

Since the ice mass conservation gives

$$
\frac{\partial\left[\rho_{\mathrm{i}} t_{\mathrm{i}} N\right]}{\partial t}=-\nabla \cdot\left(\rho_{\mathrm{i}} \vec{q}_{\text {ice }}\right)
$$

eq 1 reduces to

$$
\frac{\partial H}{\partial t}+\nabla \cdot\left(\vec{q}_{1}+\vec{q}_{\mathrm{u}}\right)=\frac{\partial}{\partial t}\left(N t_{\mathrm{i}}^{\prime}\right)
$$

Therefore, the continuity equation for the total water discharge is

$$
\frac{\partial H}{\partial t}+\frac{\partial\left(q_{\mathrm{tx}}\right)}{\partial x}+\frac{\partial\left(q_{\mathrm{ty}}\right)}{\partial y}=\frac{\partial}{\partial t}\left(N t_{\mathrm{i}}^{\prime}\right)
$$

where

$$
\begin{aligned}
H & =h+\eta=\text { total water depth } \\
\eta & =\text { water surface elevation }
\end{aligned}
$$

$$
\begin{aligned}
q_{\mathrm{tx}}= & q_{\mathrm{lx}}+q_{\mathrm{ux}}, q_{\mathrm{ty}}=q_{\mathrm{ly}}+q_{\mathrm{uy}}=\text { components } \\
& \text { of total unit width water discharge } \\
q_{\mathrm{lx}}, q_{\mathrm{ly}}= & \text { components of the unit-width water } \\
& \text { discharge beneath the ice layer } \\
q_{\mathrm{ux}}= & q_{\mathrm{ix}}+q_{\mathrm{sx}}, q_{\mathrm{uy}}=q_{\mathrm{iy}}+q_{\mathrm{sy}}=\text { water discharge } \\
& \text { in the upper ice layer } \\
q_{\mathrm{ix}}= & V_{\mathrm{ix}}\left(\eta-\eta^{\prime}\right)(1-N) \text { and } q_{\mathrm{iy}}=V_{i y}\left(\eta-\eta^{\prime}\right)(1 \\
& -N)=\text { water discharge carried by ice } \\
V_{\mathrm{ix}}, V_{\mathrm{iy}}= & \text { ice velocity } \\
q_{\mathrm{sx}}, q_{\mathrm{sy}}= & \text { components of unit-width water discharge } \\
& \text { in the ice layer relative to the moving ice } \\
& \text { or the seepage discharge in stationary ice } \\
& \text { accumulations. }
\end{aligned}
$$

When the surface ice is grounded, whether it is moving or stationary, the condition $\eta-\eta^{\prime}=\left(\rho_{\mathrm{i}} / \rho\right) t_{\mathrm{i}}$ is no longer valid, and the lower layer discharge $q_{1}$ is zero. In this case, as shown in Figure 4, the water mass conservation equation becomes

$$
\frac{\partial}{\partial t}[(1-N) \Delta \eta]=-\nabla \cdot \vec{q}_{\mathrm{u}}
$$

in which, $\Delta \eta=H$. Equation 4 can be rewritten as

and $q_{\mathrm{lx}}, q_{\mathrm{ly}}=0$.

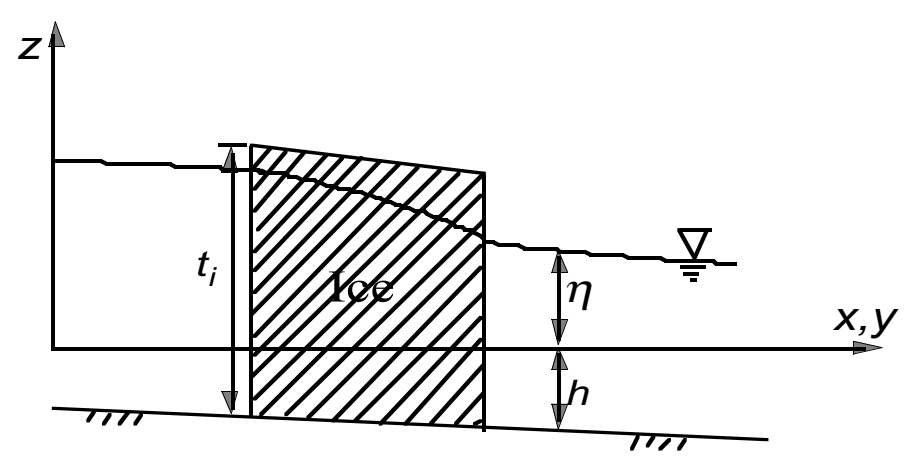

Figure 4. Definition sketch for grounded ice accumulation. 
The momentum equation in the $x$-direction for the under-ice water layer is

$$
\begin{gathered}
\frac{\partial q_{\mathrm{lx}}}{\partial t}+\frac{\partial}{\partial x}\left(\frac{q_{\mathrm{lx}}^{2}}{H^{\prime}}\right)+\frac{\partial}{\partial y}\left(\frac{q_{\mathrm{lx}} q_{\mathrm{ly}}}{H^{\prime}}\right)=\frac{1}{\rho}\left(\tau_{\mathrm{sx}}-\tau_{\mathrm{bx}}\right)+ \\
\cdot \frac{1}{\rho}\left(\frac{\partial T_{\mathrm{xx}}}{\partial x}+\frac{\partial T_{\mathrm{yx}}}{\partial y}\right)-g H^{\prime} \frac{\partial \eta}{\partial x}-M_{\mathrm{ex}}
\end{gathered}
$$

and for water in the upper ice layer it is

$$
\begin{gathered}
\frac{\partial q_{\mathrm{ux}}}{\partial t}+\frac{\partial}{\partial x}\left(\frac{q_{\mathrm{ux}}^{2}}{H_{\mathrm{u}}}\right)+\frac{\partial}{\partial y}\left(\frac{q_{\mathrm{ux}} q_{\mathrm{uy}}}{H_{\mathrm{u}}}\right)= \\
: \frac{1}{\rho} \tau_{\mathrm{ix}}-g H_{\mathrm{u}} \frac{\partial \eta}{\partial x}+M_{\mathrm{ex}}
\end{gathered}
$$

where

$H_{\mathrm{u}}=\left(\eta-\eta^{\prime}\right)(1-N)=$ net water depth in the ice layer

$\tau_{\mathrm{ix}}=$ resistance to the upper layer flow attributable to ice

$$
T_{\mathrm{jk}}=\varepsilon_{\mathrm{jk}}\left(\frac{\partial q_{\mathrm{lj}}}{\partial x_{\mathrm{k}}}+\frac{\partial q_{\mathrm{lk}}}{\partial x_{\mathrm{j}}}\right)
$$

$\varepsilon_{\mathrm{jk}}=$ generalized eddy viscosity coefficients

$j$ and $k=$ the two coordinate directions

$\vec{\tau}_{\mathrm{s}}=$ wind drag on the water surface or the ice drag on the water surface on the underside of the ice layer

$\vec{\tau}_{\mathrm{b}}=$ bed resistance to the flow

$M_{\mathrm{ex}}=$ momentum exchange at the interface of the upper ice and lower water layer,

which is

$$
\begin{gathered}
M_{\mathrm{ex}}=w_{\mathrm{wx}}\left(-\frac{\partial \eta^{\prime}}{\partial t}-w_{\mathrm{wx}} \frac{\partial \eta^{\prime}}{\partial x}-\right. \\
\left.w_{\mathrm{wy}} \frac{\partial \eta^{\prime}}{\partial y}+w_{\mathrm{wz}}\right)
\end{gathered}
$$

where, $w_{\mathrm{wx}}, w_{\mathrm{wy}}$, and $w_{\mathrm{wz}}$ are components of water velocity at the interface between ice and water layers. When eq 6 and 7 are combined and the unit-width discharges are expressed in terms of hydraulic conveyance, i.e., $q=K S_{\mathrm{f}}^{1 / 2}$, the momentum equation becomes

$$
\begin{gathered}
\frac{\partial q_{\mathrm{tx}}}{\partial t}+\frac{\partial}{\partial x} \frac{q_{\mathrm{tx}}^{2}}{K_{\mathrm{t}}^{2}}\left(\frac{K_{1}^{2}}{H^{\prime}}+\frac{K_{\mathrm{u}}^{2}}{H_{\mathrm{u}}}\right)+\frac{\partial}{\partial y} \frac{q_{\mathrm{tx}} q_{\mathrm{ty}}}{K_{\mathrm{t}}^{2}}\left(\frac{K_{1}^{2}}{H^{\prime}}+\right. \\
\left.\cdot \frac{K_{\mathrm{u}}^{2}}{H_{\mathrm{u}}}\right)=\frac{1}{\rho}\left(\tau_{\mathrm{ix}}+\tau_{\mathrm{sx}}-\tau_{\mathrm{bx}}\right) \\
-g\left(H_{\mathrm{u}}+H^{\prime}\right) \frac{\partial \eta}{\partial x}+\frac{1}{\rho}\left(\frac{\partial T_{\mathrm{xx}}}{\partial x}+\frac{\partial T_{\mathrm{yx}}}{\partial y}\right)
\end{gathered}
$$

where

$K_{1}=$ conveyance of the lower water layer

$K_{\mathrm{u}}=$ conveyance of the upper ice layer

$K_{\mathrm{t}}=$ total conveyance

$$
\begin{aligned}
K_{\mathrm{u}} & =K_{\mathrm{s}}+K_{\mathrm{i}} \\
K_{\mathrm{s}} & =\text { conveyance of seepage flow } q_{\mathrm{s}} \\
K_{\mathrm{i}} & =\text { conveyance of flow carried by ice. }
\end{aligned}
$$

The conveyance

$$
K_{\mathrm{s}}=\lambda \frac{H_{\mathrm{u}}}{1-N}=\lambda\left(\eta-\eta^{\prime}\right)
$$

where $\lambda$ is a seepage coefficient defined by (Bear 1972)

$$
\lambda=\sqrt{k \frac{p^{3}}{1-p} g d_{\mathrm{s}}}
$$

in which

$$
\begin{aligned}
d_{\mathrm{S}} & =\sigma / M_{\mathrm{S}} \\
p & =\text { porosity } \\
M_{\mathrm{S}} & =\text { average surface area per volume } \\
k & =\text { dimensionless empirical coefficient. }
\end{aligned}
$$

For randomly placed square plastic blocks $(5 \times 5 \times$ $0.6 \mathrm{~cm}$ and $10 \times 10 \times 1.3 \mathrm{~cm}$ ), Beltaos and Wong (1986) found $k=0.70$. Applications to the Credit River ice jams by Beltaos (1993a) gave an average $\lambda$ value of $1.6 \mathrm{~m} / \mathrm{s}$. For the Restigouche and Rushoon Rivers, Beltaos (1993a) used 2.5 and $1.0 \mathrm{~m} / \mathrm{s}$. In this study a value of $\lambda=1.0 \mathrm{~m} / \mathrm{s}$ is used for freezeup conditions. The conveyance $K_{1}$ is

$$
K_{1}=\frac{H^{\prime}\left(\alpha_{\mathrm{h}} H^{\prime}\right)^{\frac{2}{3}}}{n_{\mathrm{b}}} .
$$

The factor $\alpha_{\mathrm{h}}$ is the fraction of the total water flow depth affected by the bed friction. Shen et al. (1990) discussed the distribution of shear stresses on the channel bed and the interface between the moving ice layer and the water current underneath it, and derived the expression for the coefficient $\alpha_{h}$ as

$$
\alpha_{\mathrm{h}}=\frac{1}{1+\frac{A_{\mathrm{i}}}{A_{\mathrm{b}}}}=\frac{1}{1+\left[\frac{n_{\mathrm{i}}^{2}}{n_{\mathrm{b}}^{2}} \frac{N\left(V_{\mathrm{w}}-u\right)^{2}}{V_{\mathrm{w}}^{2}}\right]^{3 / 4}}
$$

in which

$A_{\mathrm{i}}=$ flow area affected by ice resistance

$A_{\mathrm{b}}=$ flow area affected by bed resistance

$n_{\mathrm{i}}=$ Manning's coefficient for ice

$n_{\mathrm{b}}=$ Manning's coefficient for the bed

$V_{\mathrm{w}}=$ depth-averaged current velocity

$u=$ ice velocity.

$K_{\mathrm{i}}$ is estimated as

$$
K_{\mathrm{i}}=\frac{\frac{q_{\mathrm{i}}}{q_{\mathrm{t}}}\left(K_{1}+K_{\mathrm{s}}\right)}{1-\frac{q_{\mathrm{i}}}{q_{\mathrm{t}}}}
$$

where $\vec{q}_{\mathrm{i}}=\vec{V}_{\mathrm{i}} H_{\mathrm{u}}$. 
Similarly, the $y$-component of the momentum equation is

$$
\begin{aligned}
\frac{\partial q_{\mathrm{ty}}}{\partial t}+ & \frac{\partial}{\partial x} \frac{q_{\mathrm{tx}} q_{\mathrm{ty}}}{K_{\mathrm{t}}^{2}}\left(\frac{K_{1}^{2}}{H^{\prime}}+\frac{K_{\mathrm{u}}^{2}}{H_{\mathrm{u}}}\right)+\frac{\partial}{\partial y} \frac{q_{\mathrm{ty}}^{2}}{K_{\mathrm{t}}^{2}}\left(\frac{K_{1}^{2}}{H^{\prime}}+\frac{K_{\mathrm{u}}^{2}}{H_{\mathrm{u}}}\right)= \\
& \frac{1}{\rho}\left(\tau_{\mathrm{iy}}+\tau_{\mathrm{sy}}-\tau_{\mathrm{by}}\right) \\
& -g\left(H_{\mathrm{u}}+H^{\prime}\right) \frac{\partial \eta}{\partial y}+\frac{1}{\rho}\left(\frac{\partial T_{\mathrm{xy}}}{\partial x}+\frac{\partial T_{\mathrm{yy}}}{\partial y}\right) .
\end{aligned}
$$

The flow model solves for components of $\vec{q}_{\mathrm{t}}$ and the water depth $H$ using eq 3, 9, and 11. A finite-element model with the lumping technique and leapfrog time integration (Connor and Brebbia 1978, Wake and Xiao 1989 ) is used. The bed shear stresses can be expressed as

$$
\begin{aligned}
\tau_{\mathrm{bx}} & =c_{\mathrm{f}} \rho \frac{q_{\mathrm{x}}\left(q_{\mathrm{x}}^{2}+q_{\mathrm{y}}^{2}\right)^{1 / 2}}{H^{\prime 2}} \\
\tau_{\mathrm{by}} & =c_{\mathrm{f}} \rho \frac{q_{\mathrm{y}}\left(q_{\mathrm{x}}^{2}+q_{\mathrm{y}}^{2}\right)^{1 / 2}}{H^{\prime 2}}
\end{aligned}
$$

in which the friction coefficient $c_{\mathrm{f}}$ can be expressed in terms of Manning's coefficients of the bed and the shear stress distribution coefficient $\alpha_{h}$ as

$$
c_{\mathrm{f}}=\frac{n_{\mathrm{b}}^{2}}{\alpha_{\mathrm{h}} H^{\prime 1 / 3}} g .
$$

On the open water surface, the surface shear stress attributable to wind effect can be expressed as

$$
\begin{aligned}
& \tau_{\mathrm{sx}}^{(\mathrm{a}-\mathrm{w})}=\rho_{\mathrm{a}} \gamma^{2} W^{2} \cos \theta_{\mathrm{a}} \\
& \tau_{\mathrm{sy}}^{(\mathrm{a}-\mathrm{w})}=\rho_{\mathrm{a}} \gamma^{2} W^{2} \sin \theta_{\mathrm{a}}
\end{aligned}
$$

in which

$$
\begin{aligned}
\gamma^{2}= & \text { wind drag coefficient }(\mathrm{Wu} 1973) \\
W= & \text { wind velocity at } 10 \mathrm{~m} \text { above the water } \\
& \text { surface } \\
\rho_{\mathrm{a}}= & \text { density of air } \\
\theta_{\mathrm{a}}= & \text { angle between the wind direction and the } \\
& x \text {-axis. }
\end{aligned}
$$

For a fully ice-covered water surface, the surface shear stress components on the water can be written as

$$
\tau_{\mathrm{sx}}^{(\mathrm{i}-\mathrm{w})}=\rho c_{\mathrm{w}}\left|\vec{V}_{\mathrm{i}}-\vec{V}_{\mathrm{w}}\right|\left(u-V_{\mathrm{wx}}\right)
$$

$$
\tau_{\mathrm{sy}}^{(\mathrm{i}-\mathrm{w})}=\rho c_{\mathrm{w}}\left|\vec{V}_{\mathrm{i}}-\vec{V}_{\mathrm{w}}\right|\left(v-V_{\mathrm{wy}}\right)
$$

in which

$$
\begin{aligned}
\vec{V}_{\mathrm{w}}=\frac{\vec{q}}{H^{\prime}}= & \text { water current velocity } \\
\vec{V}_{\mathrm{i}}=u \vec{i}+v \vec{j}= & \text { ice velocity } \\
c_{\mathrm{w}}= & \text { water drag coefficient on ice, which } \\
& \text { varies with ice concentration and ice } \\
& \text { floe geometry. }
\end{aligned}
$$

This coefficient can be related to Manning's coefficient of the underside of the cover as

$$
c_{\mathrm{w}}=\frac{n_{\mathrm{i}}^{2} g}{\left[\left(1-\alpha_{\mathrm{h}}\right) H^{\prime}\right]^{1 / 3}} .
$$

For a partially ice-infested water surface, the surface shear stress is assumed to be a linear combination of $\tau_{\mathrm{s}}^{(\mathrm{a}-\mathrm{w})}$ and $\tau_{\mathrm{s}}^{(\mathrm{i}-\mathrm{w})}$

$$
\vec{\tau}_{\mathrm{s}}=(1-N) \vec{\tau}_{\mathrm{s}}^{(\mathrm{a}-\mathrm{w})}+N \vec{\tau}_{\mathrm{s}}{ }^{(\mathrm{i}-\mathrm{w})}
$$

The drag of the seepage flow on ice is

$$
\begin{gathered}
\tau_{\mathrm{ix}}=-\rho g H_{\mathrm{u}} \frac{q_{\mathrm{s}} q_{\mathrm{sx}}}{K_{\mathrm{s}}^{2}} \\
\tau_{\text {iy }}=-\rho g H_{\mathrm{u}} \frac{q_{\mathrm{s}} q_{\mathrm{sy}}}{K_{\mathrm{s}}^{2}} .
\end{gathered}
$$

\section{Ice dynamic model}

The momentum equation of the surface ice can be written in the Lagrangian form as (Shen et al. 1990)

$$
M_{\mathrm{i}} \frac{D \vec{V}_{\mathrm{i}}}{D t}=\vec{R}+\vec{F}_{\mathrm{a}}+\vec{F}_{\mathrm{w}}+\vec{G}
$$

in which

$$
\begin{aligned}
\frac{D \vec{V}_{\mathrm{i}}}{D t} & =\text { acceleration of ice } \\
\vec{M}_{\mathrm{i}} & =\rho_{\mathrm{i}} N t_{\mathrm{i}}=\text { ice mass per unit area } \\
\vec{R} & =\text { internal ice resistance } \\
\vec{F}_{\mathrm{a}} & =\text { wind drag } \\
\vec{F}_{\mathrm{w}} & =\text { water drag } \\
\vec{G} & =\text { gravitational force } \\
\rho_{\mathrm{i}} & =\text { density of ice } \\
N & =\text { concentration of ice } \\
t_{\mathrm{i}} & =\text { thickness of ice. }
\end{aligned}
$$

Force terms in the momentum equation can be expressed in two-dimensional forms as follows. 
Internal ice resistance $(\overrightarrow{\mathrm{R}})$

$$
\begin{aligned}
& \vec{R}=R_{\mathrm{x}} \vec{i}+R_{\mathrm{y}} \vec{j} \\
& R_{\mathrm{x}}=\frac{\partial}{\partial x}\left(\sigma_{\mathrm{xx}} N t_{\mathrm{i}}\right)+\frac{\partial}{\partial y}\left(\sigma_{\mathrm{xy}} N t_{\mathrm{i}}\right) \\
& R_{\mathrm{y}}=\frac{\partial}{\partial y}\left(\sigma_{\mathrm{yy}} N t_{\mathrm{i}}\right)+\frac{\partial}{\partial x}\left(\sigma_{\mathrm{yx}} N t_{\mathrm{i}}\right)
\end{aligned}
$$

in which, $\sigma_{\mathrm{xx}}, \sigma_{\mathrm{yy}}=$ normal stress components, and $\sigma_{\mathrm{xy}}=\sigma_{\mathrm{yx}}=$ shear stress components. These stresses can be determined by the constitutive relationship.

Wind drag at the air-ice interface $\left(\overrightarrow{\mathrm{F}}_{a}\right)$

$$
\begin{aligned}
\vec{F}_{\mathrm{a}} & =\left(\tau_{\mathrm{ax}} N\right) \vec{i}+\left(\vec{\tau}_{\mathrm{ay}} N\right) \vec{j} \\
\tau_{\mathrm{ax}} & =\rho_{\mathrm{a}} c_{\mathrm{a}}|\vec{W}| W_{\mathrm{x}} \\
\tau_{\mathrm{ay}} & =\rho_{\mathrm{a}} c_{\mathrm{a}}|\vec{W}| W_{\mathrm{y}}
\end{aligned}
$$

in which

$$
\begin{aligned}
\vec{W}= & W_{\mathrm{x}} \vec{i}+W_{\mathrm{y}} \vec{j}=\text { wind velocity at } 10 \mathrm{~m} \text { above } \\
& \text { the water surface } \\
\rho & =\text { density of air } \\
c_{\mathrm{a}} & =\text { wind drag coefficient. }
\end{aligned}
$$

Water drag at the ice-water interface $\left(\vec{F}_{w}\right)$

$$
\begin{aligned}
& \vec{F}_{\mathrm{w}}=\left(\tau_{\mathrm{wx}} N\right) \vec{i}+\left(\vec{\tau}_{\mathrm{wy}} N\right) j \\
& \tau_{\mathrm{wx}}=-\rho c_{\mathrm{w}}\left|\vec{V}_{\mathrm{w}}-\vec{V}_{\mathrm{i}}\right|\left(u-V_{\mathrm{wx}}\right) \\
& \tau_{\mathrm{wy}}=-\rho c_{\mathrm{w}}\left|\vec{V}_{\mathrm{w}}-\vec{V}_{\mathrm{i}}\right|\left(v-V_{\mathrm{wy}}\right)
\end{aligned}
$$

Gravitational force ascribable to the water surface slope $(\vec{G})$

$$
\begin{aligned}
\vec{G} & =G_{\mathrm{x}} \vec{i}+G_{\mathrm{y}} \vec{j} \\
G_{\mathrm{x}} & =-M_{\mathrm{i}} g \frac{\partial \eta}{\partial x} \\
G_{\mathrm{y}} & =-M_{\mathrm{i}} g \frac{\partial \eta}{\partial y} .
\end{aligned}
$$

The ice mass conservation equation is

$$
\frac{\partial M_{\mathrm{i}}}{\partial t}+\frac{\partial M_{\mathrm{i}} u}{\partial x}+\frac{\partial M_{\mathrm{i}} v}{\partial y}=0
$$

This equation can also be written as

$$
\frac{D M_{\mathrm{i}}}{D t}+M_{\mathrm{i}} \nabla \cdot \vec{V}=0 .
$$

Since the ice mass per unit area, $M_{\mathrm{i}}$, is determined by the ice concentration and the ice layer thickness, one more conservation equation is needed. The equation of conservation of ice area within an elemental area can be obtained by considering the ice area flux into and out of the control area and mechanical redistribution.

$$
\frac{D N}{D t}+N \nabla \cdot \vec{V}+R_{\mathrm{a}}=0
$$

in which $R_{\mathrm{a}}=$ rate of change of ice area attributable to mechanical redistribution.

A Lagrangian discrete-parcel method (DPM) (Shen and Chen 1992, Shen et al. 1993) is used to simulate the dynamics of the ice transport. The basic concept of the discrete-parcel method is that the ice, considered as a continuum, can be represented by a sufficiently large number of individual parcels. Each parcel has welldefined properties, such as mass, concentration, thickness, and velocity, and is deformable in shape. Ice properties at parcel locations or finite-element nodes can be interpolated from the properties of parcels within the close vicinity. The theoretical background underlying this method is the smoothed particle hydrodynamics (SPH) developed by Lucy (1977) and Gingold and Monaghan (1977).

Unlike the original smoothed particle hydrodynamics, the present discrete-parcel model deals with ice movement in a bounded domain, such as a river or a lake. A natural boundary condition at a stationary boundary is a partial-slip boundary condition with zero normal ice flux. As an ice parcel moves along a solid boundary, it is subjected to a frictional force. The method of images is used in this model for such a boundary condition.

This model applies a dynamic Mohr-Coulomb yield criterion to calculate the boundary frictional force as follows

$$
F_{\mathrm{f}}=F_{\mathrm{c}}+F_{\mathrm{N}} \tan \phi_{\mathrm{B}}
$$

in which

$$
\begin{aligned}
F_{\mathrm{f}}= & \text { frictional force between ice and the solid } \\
& \text { boundary } \\
F_{\mathrm{c}}= & \text { ice cohesive force }, \text { assumed to be zero } \\
F_{\mathrm{N}}= & \text { normal ice force against the boundary } \\
\phi_{\mathrm{B}}= & \text { dynamic friction angle. }
\end{aligned}
$$

\section{Constitutive law}

In order to calculate the internal ice resistance, a constitutive law relating stresses with the motion of ice is required. The most widely used constitutive law for ice dynamics is the viscous-plastic law (Hibler 1979, 
Wake and Rumer 1983, Shen et al. 1993). The present study uses the Mohr-Coulomb yield criterion (Gutfraind and Savage 1997), i.e.

$$
\sigma_{1} \pm \sigma_{2}=\left(\sigma_{1}+\sigma_{2}\right) \sin \phi
$$

where $\sigma_{1}$ and $\sigma_{2}$ are the principal stresses and $\phi$ is the internal friction angle. The internal stress is expressed in terms of a nonlinear viscosity $\mu$, as follows:

$$
\sigma_{\mathrm{ij}}=2 \mu \dot{\varepsilon}_{\mathrm{ij}}-\mu \dot{\varepsilon}_{\mathrm{kk}} \delta_{\mathrm{ij}}-P \delta_{\mathrm{ij}}
$$

where $\dot{\varepsilon}_{\mathrm{ij}}$ is the strain rate tensor. Assuming that the principal axes of stress and strain rate coincide, we can express the viscosity as

$$
\mu=\min \left\{\frac{P \sin \phi}{\dot{\varepsilon}_{1}-\dot{\varepsilon}_{2}}, \mu_{\max }\right\}
$$

where $\dot{\varepsilon}_{1}$ and $\dot{\varepsilon}_{2}$ are the principal components of the strain rate tensor and $\mu_{\max }$, the maximum value of the viscosity, determines whether the stress state is inside or on the yield envelope. When $\mu=\mu_{\max }$, the ice will flow as a viscous fluid, whereas it will flow in a plastic manner when $\mu$ is smaller than $\mu_{\max }$. The following expression obtained by extending the constitutive relationship for static ice jams (Shen et al. 1990) is used to determine the pressure $P$ :

$$
\begin{gathered}
P=-\left(\sigma_{1}+\sigma_{2}\right) / 2=\frac{1}{2}\left[1+\tan ^{2}\left(\frac{\pi}{4} \pm \frac{\phi}{2}\right)\right] \\
\left(1-\frac{\rho_{\mathrm{i}}}{\rho}\right) \frac{\rho_{\mathrm{i}} g t_{\mathrm{i}}}{2}\left(\frac{N}{N_{\max }}\right)^{\mathrm{j}}
\end{gathered}
$$

in which $j=15$, an empirical constant, and the + and signs are for convergent and divergent states, respectively.

\section{Initial and boundary conditions}

\section{Hydrodynamics}

Initial values of unit discharges $q_{\mathrm{x}}, q_{\mathrm{y}}$, and water level $\eta$ at every finite-element node have to be specified for the hydrodynamic simulation. A steady-state condition that corresponds to the specified boundary conditions at $t=0$ is generated with the model and used as the initial conditions for $q_{\mathrm{x}}, q_{\mathrm{y}}$, and $\eta$. Boundary conditions used are the water level at the downstream boundary and discharge at the upstream boundary. The unit normal discharge distribution across the upstream boundary is estimated by the stream-tube method. The calculated unit-discharge distribution is adjusted to ensure that the water level across the width of the boundary is constant. Along land boundaries, such as shorelines and dikes, the unit normal discharges at the finite-element nodes along the boundary are set to be zero. Since the hydrodynamic model is a depth-averaged model, it is assumed that the floating ice boom does not affect the flow condition. However, if the boom configuration can significantly affect the flow, an internal boundary condition may be added.

\section{Ice dynamics}

Initial conditions for ice dynamic simulations are ice concentration, ice velocity, and ice thickness in the channel. Ice thickness, ice concentration, and ice velocity are required upstream boundary conditions. External and internal forces acting on the ice govern the boundary ice velocity. However, when the ice concentration is not very high, the internal ice resistance is not significant, which is usually the case at the upstream boundary, and the ice velocity at the upstream boundary may be approximated by the water velocity.

\section{Limiting conditions for ice accumulation behind the boom}

When surface ice arrives at the boom from upstream, it may stop behind the boom to accumulate into an ice cover. However, if the current velocity exceeds a critical entrainment velocity, the surface ice will submerge and be transported downstream. If the flow condition permits the accumulation of the ice rubble behind the boom, the upstream progression is limited by the possible entrainment of surface ice at the upstream edge of the ice accumulation. In addition, an increase in the current velocity beneath the ice accumulation, caused either by the thickening of the cover or an increase in water discharge, can erode ice particles from the underside of the cover and limit its progression. Neither surface ice entrainment nor undercover erosion was considered in the lake ice boom simulation model of Shen et al. (1997), owing to the low current velocity in lakes. The critical condition for ice accumulation behind a lake ice boom is the spillover of ice rubble when the boom load exceeds a critical value. This condition should also be considered for river ice booms. However, owing to the increased effect of bank resistance, the ice load on river ice booms rapidly approaches a limiting value as the ice cover progresses a few channel widths upstream (Latyshenkov 1946, Tuthill and Gooch 1998).

In this section, the limiting conditions for ice accumulation behind boom will be discussed.

\section{Ice entrainment condition at the boom and the leading edge of the ice cover}

When water velocity is high, surface ice arriving at the boom will submerge and pass under it. Past field experience suggests that ice retention is possible at river locations where the surface water velocity is at or below 
$0.7 \mathrm{~m} / \mathrm{s}(2.25 \mathrm{ft} / \mathrm{s})$ and the channel Froude number

$$
(V / \sqrt{g h})
$$

does not exceed 0.08. Ashton (1974) analyzed the surface stability of floating ice blocks and obtained the following submergence condition:

$$
F_{\mathrm{c}}=\frac{V_{\mathrm{c}}}{\sqrt{g t\left(1-\frac{\rho_{\mathrm{i}}}{\rho}\right)}}=\frac{2\left(1-\frac{t_{\mathrm{b}}}{H}\right)}{\left[5-3\left(1-\frac{t_{\mathrm{b}}}{H}\right)^{2}\right]^{1 / 2}}
$$

where

$$
\begin{aligned}
V_{\mathrm{c}} & =\text { water velocity upstream of the ice block } \\
t_{\mathrm{b}} & =\text { ice block thickness } \\
H & =\text { flow depth upstream of the accumulation. }
\end{aligned}
$$

This formula compared well with experimental data. Larsen (1975) studied the stability of thin blocks and showed that $F_{\mathrm{c}}$ is much larger than 1.4 when $\left(t_{\mathrm{b}} / H\right)<0.1$. Daly and Axelson (1990) further refined these studies. More recent field studies showed that, under certain conditions, specially designed booms can perform successfully at water velocities as high as $0.76 \mathrm{~m} / \mathrm{s}(2.5 \mathrm{ft} / \mathrm{s})$ and Froude numbers above 0.12 (White 1992). Results of a recent 1:25 scale physical model study by Tuthill and Gooch (1998) support existing ice entrainment criteria, finding that $0.3-\mathrm{m}$-thick-ice blocks submerge in a $4.5-\mathrm{m}$-deep channel at a velocity of about $0.76 \mathrm{~m} / \mathrm{s}(2.5$ $\mathrm{ft} / \mathrm{s}$ ) (all units prototype), and a channel Froude number of 0.1 .

\section{Erosion of ice on the underside of ice jams}

When an ice jam forms, its thickness may be limited by the stability of ice particles on its underside. As the jam thickens near its downstream end, the water flow area decreases, increasing water velocity and shear on the ice underside. The shear may become large enough to erode ice pieces from the jam's underside and transport them downstream. Thinning the downstream end of the jam by erosion lowers the water level at the upstream end, increasing the velocity and the tendency for ice entrainment. This process of underice erosion near the toe and entrainment at the upstream end of the jam may be sufficient to halt upstream progression.

The stability of ice floes on the underside of an ice cover or ice jam has been investigated by Ashton (1974), Uzuner (1977), Tatinclaux and Gogus (1981), and Daly and Axelson (1990). Tatinclaux and Gogus (1981) recommended an empirical stability criterion in terms of the critical Froude number $F_{\mathrm{e}, \mathrm{c}}$ and the floe aspect ratio $t_{\mathrm{b}} / L$

$$
\begin{aligned}
& F_{\mathrm{e}, \mathrm{c}}=\frac{V_{\mathrm{e}}}{\sqrt{g t_{\mathrm{b}}\left(1-\frac{\rho_{\mathrm{i}}}{\rho}\right)}}=\left[-2.26\left(\frac{t_{\mathrm{b}}}{L}\right)^{2}+\right. \\
& \left.2.14 \frac{t_{\mathrm{b}}}{L}+0.015\right]^{-1 / 2}
\end{aligned}
$$

where $V_{\mathrm{c}}=$ flow velocity below the cover and $L=$ length of ice floe. The experimental study of Kawai et al. (1997) showed that the critical Froude number depends not only on $t_{\mathrm{b}} / L$. For different floe sizes, their experimental results showed that the $F_{\mathrm{e}, \mathrm{c}}=f\left(t_{\mathrm{b}} / L\right)$ relationships are different. This shows the complexity of the problem, and the difficulty in describing the mechanism by a simple formula. For typical Missouri River ice floes of thickness $t_{\mathrm{b}}=0.15 \mathrm{~m}$, and size $L=1.5$ $\sim 6 \mathrm{~m}$, eq 40 gives $V_{\mathrm{e}, \mathrm{c}}=0.76 \sim 1.4 \mathrm{~m} / \mathrm{s}$. In a $1: 25$ physical model test with natural ice scaled to the observed ice size distribution of the Missouri River ice, Tuthill and Gooch (1998) measured an erosion velocity to be about $1.5 \mathrm{~m} / \mathrm{s}(5 \mathrm{ft} / \mathrm{s})$.

\section{Boom submergence condition}

The present model assumes that each span of the ice boom is designed to submerge and to allow ice to overtop it when a critical value of cable tension is exceeded (Shen et al. 1997). When the load is reduced and the weight of the ice above the boom is smaller than the net buoyancy of the boom, the boom will rise again to prevent ice from passing through. The value of critical cable tension, which varies with the geometry and size of booms, has to be specified for the model simulation.

\section{Ice load on the boom}

When the boom stops the ice movement, mechanical thickening will occur and the internal stress will build up quickly in the ice rubble. The load on the boom and the span cable tension can be calculated from the ice rubble stresses.

Consider a triangular differential element of ice rubble $a b c$ (Fig. 5) in contact with the boom, which has a finite thickness $t_{\mathrm{i}}$. The total force acting in the $x$ direction is

$$
\begin{aligned}
& \sum F_{\mathrm{x}}=-\sigma_{\mathrm{xx}} N t_{\mathrm{i}} d y-\sigma_{\mathrm{yx}} N t_{\mathrm{i}} d x+X N t_{\mathrm{i}} d l+ \\
& \frac{1}{2} \tau_{\mathrm{sx}} N d x d y+\frac{1}{2} \tau_{\mathrm{wx}} N d x d y+\frac{1}{2} \rho_{\mathrm{i}} g N t_{\mathrm{i}} d x d y \frac{\partial \eta}{\partial x} .
\end{aligned}
$$

The total force acting in the $y$-direction is

$$
\begin{aligned}
& \sum F_{\mathrm{y}}=-\sigma_{\mathrm{yy}} N t_{\mathrm{i}} d x-\sigma_{\mathrm{xy}} N t_{\mathrm{i}} d y+Y N t_{\mathrm{i}} d l+ \\
& \frac{1}{2} \tau_{\mathrm{sy}} N d x d y+\frac{1}{2} \tau_{\mathrm{wy}} N d x d y+\frac{1}{2} \rho_{\mathrm{i}} g N t_{\mathrm{i}} d x d y \frac{\partial \eta}{\partial y}
\end{aligned}
$$




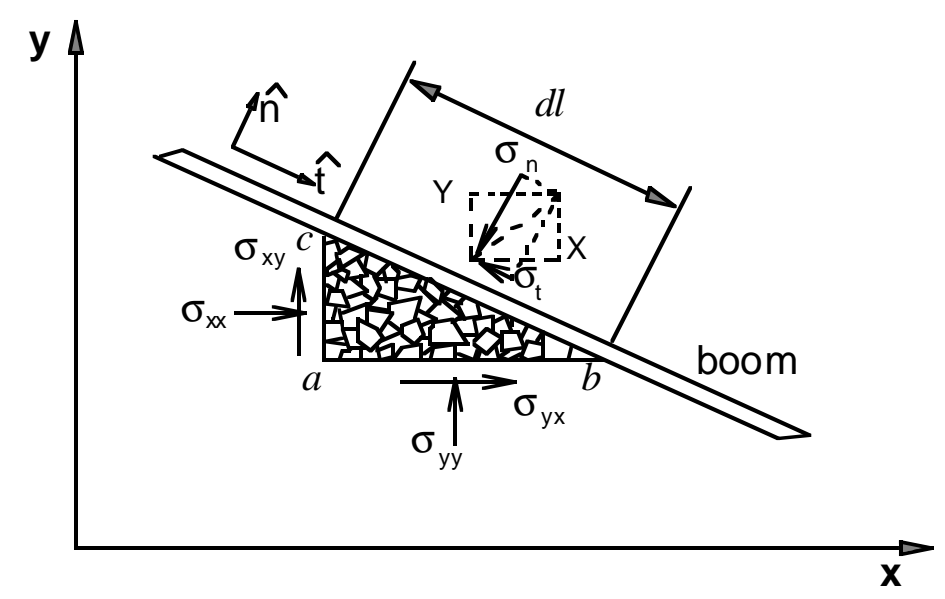

Figure 5. Interaction of a differential element of ice rubble with the boom.

in which

$$
\begin{aligned}
X \text { and } Y= & x \text { - and } y \text {-components of the ice load on the } \\
& \text { boom } \\
N= & \text { ice concentration } \\
\tau_{\mathrm{sx}}, \tau_{\mathrm{sy}}= & \text { components of wind drag in } x \text { - and } \\
& y \text {-directions } \\
\tau_{\mathrm{wx}}, \tau_{\mathrm{wy}}= & \text { components of water drag in } x \text { - and } \\
& y \text {-directions. }
\end{aligned}
$$

Since the ice element is essentially stationary, the force balance conditions $\sum F_{\mathrm{x}}=0$ and $\sum F_{\mathrm{y}}=0$ reduce the above equations to the following, by neglecting the higher order terms

$$
\begin{aligned}
& X=\sigma_{\mathrm{xx}} \cos (n, x)+\sigma_{\mathrm{yx}} \cos (n, y) \\
& Y=\sigma_{\mathrm{yy}} \cos (n, y)+\sigma_{\mathrm{xy}} \cos (n, x) .
\end{aligned}
$$

The normal and shear stresses acting on the boom segment $a b$ are

$$
\begin{gathered}
\sigma_{\mathrm{n}}=\sigma_{\mathrm{xx}} \cos ^{2}(n, x)+\sigma_{\mathrm{yy}} \cos ^{2}(n, y)+ \\
2 \sigma_{\mathrm{xy}} \cos (n, x) \cos (n, y) \\
\sigma_{\mathrm{t}}=\left(\sigma_{\mathrm{yy}}-\sigma_{\mathrm{xx}}\right) \cos (n, x) \cos (n, y)+ \\
\cdot \sigma_{\mathrm{xy}} \cos ^{2}(n, x)-\sigma_{\mathrm{yx}} \cos ^{2}(n, y) .
\end{gathered}
$$

The normal and tangential components of the load per unit length of the boom are

$$
\begin{aligned}
& P_{\mathrm{n}}=N t_{\mathrm{i}} \sigma_{\mathrm{n}} \\
& P_{\mathrm{t}}=N t_{\mathrm{i}} \sigma_{\mathrm{t}} .
\end{aligned}
$$

\section{MODEL VERIFICATION AND CALIBRATION}

\section{Verification of the hydrodynamic model with a uniform ice cover}

The hydrodynamics model is verified by simulating flow in a rectangular ice-covered channel of length 2000 $\mathrm{m}$, width $500 \mathrm{~m}$, bed elevation at upstream $5 \mathrm{~m}$, bottom slope 0.0001 , and bed Manning's coefficient of 0.03 . The ice cover thickness is selected to be $1.06 \mathrm{~m}$, with a Manning's coefficient 0.03 . Water discharge is 2500 $\mathrm{m}^{3} / \mathrm{s}$ and downstream water surface elevation is -0.2 $\mathrm{m}$. The simulated water surface profile is compared with the result of the one-dimensional backwater calculation in Figure 6.

\section{Analytical solutions for river ice jams}

Analytical solutions for idealized ice jams in a straight, uniform, rectangular channel with a uniform current are developed for verifying the numerical model. The numerical simulation results are compared with analytical solutions for ice accumulation in a channel of length $5000 \mathrm{~m}$, width $500 \mathrm{~m}$, constant water velocity of $0.6 \mathrm{~m} / \mathrm{s}$, and zero water surface slope. A boom is placed at $500 \mathrm{~m}$ and assumed $100 \%$ effective, i.e., no ice is allowed to pass it. Initially, 900 ice parcels of size $50 \times 50 \mathrm{~m}$ having a thickness of $0.2 \mathrm{~m}$ and a concentration of 0.6 are placed over the water surface from the upstream boundary and the boom. In the simulations, this ice cover was allowed to move and consolidate behind the boom under the action of the current drag. No additional ice was added during the simulations. The model parameters used are summarized in Table 1. 


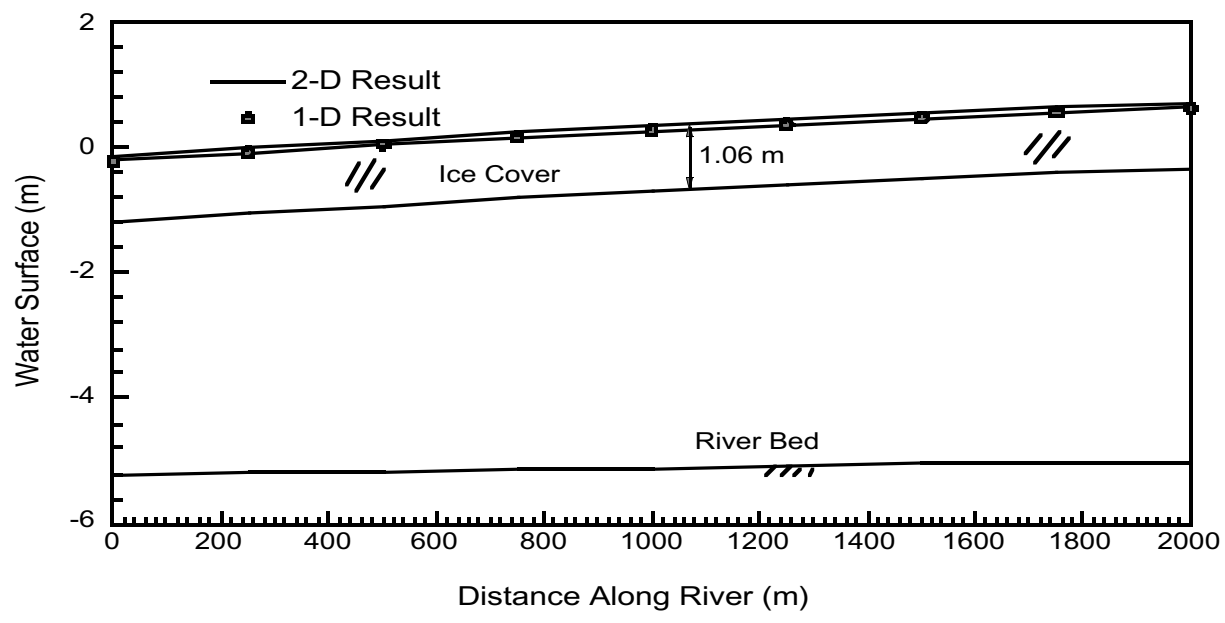

Figure 6. Comparison of water surface profiles.

\section{Without bank friction}

The steady-state ice thickness profile can be obtained by simplifying the momentum equation, eq 22 . When only the water drag in $x$-direction, i.e., $F_{\mathrm{wx}}=\rho c_{\mathrm{w}} V_{\mathrm{wx}}^{2}$, is considered and the bank friction is neglected, the ice momentum equation is simplified to $R_{\mathrm{x}}+F_{\mathrm{wx}}=0$. The internal ice resistance reduces to

$$
R_{\mathrm{x}}=\frac{\partial}{\partial x}\left(\sigma_{\mathrm{xx}} N t_{\mathrm{i}}\right)+\frac{\partial}{\partial y}\left(\sigma_{\mathrm{xy}} N t_{\mathrm{i}}\right)=\frac{\partial}{\partial x}\left(P N t_{\mathrm{i}}\right) .
$$

Using eq 37 for the pressure term leads to a simple analytical solution for the static ice accumulation thickness profile

$$
t_{\mathrm{i}}=\left(t_{\mathrm{i} 0}^{2}+\frac{2 \rho c_{\mathrm{W}} V_{\mathrm{wx}}^{2}}{\tan ^{2}\left(\frac{\pi}{4}+\frac{\phi}{2}\right)\left(1-\frac{\rho_{\mathrm{i}}}{\rho}\right) \rho_{\mathrm{i}} g} x\right)^{\frac{1}{2}}
$$

in which $t_{\mathrm{i} 0}=$ single layer ice thickness and $x=$ distance from the leading edge of the jam where $t_{\mathrm{i}}=t_{\mathrm{i} 0}$. The simulated results and analytical solution are compared in Figure 7. Figure 7a shows progressive thickening and compressing of the simulated ice cover with time. Figure $7 \mathrm{~b}$ compares the analytical solution to the simulated ice thickness profile on and after $t=4$ hours.

\section{With bank friction}

An analytical solution for the width-averaged ice jam thickness profile can be derived by extending the solution of Pariset and Hausser (1961).

$$
t_{\mathrm{i}}=t_{\mathrm{eq}}\left(1-e^{-\frac{2 \mu_{1}}{B} \times}\right)^{\frac{1}{2}}
$$

where $B$ is the channel width and the equilibrium ice thickness is

$$
t_{\mathrm{eq}}=\left(\frac{B N C_{\mathrm{w}} V_{\mathrm{wx}}^{2}}{g \mu_{2} \frac{\rho_{\mathrm{i}}}{\rho}\left(1-\frac{\rho_{\mathrm{i}}}{\rho}\right)}\right)^{\frac{1}{2}}
$$

where

$$
\mu_{2}=N \tan \phi(1+\sin \phi)
$$

and For

$$
\mu_{1}=\tan \phi(1-\sin \phi)(\text { Beltaos 1995) }
$$

$$
\begin{aligned}
\phi & =46^{\circ} \\
\mu_{2} & =1.068 \\
\mu_{1} & =0.29 .
\end{aligned}
$$

\begin{tabular}{|llc|}
\hline \multicolumn{2}{|l|}{ Table 1. Parameters used in the ice dynamic } \\
simulation. \\
Parameter & \multicolumn{1}{l}{ Description } & Value \\
\hline$N_{\max }$ & Maximum ice concentration & 0.6 \\
$\phi$ & Internal friction angle of ice & $46^{\circ}$ \\
$\tan \phi$ & Boundary friction coefficient & 1.04 \\
$j$ & Empirical constant & 15 \\
$C_{\mathrm{w}}$ & Water drag coefficient on ice & 0.02 \\
\hline
\end{tabular}




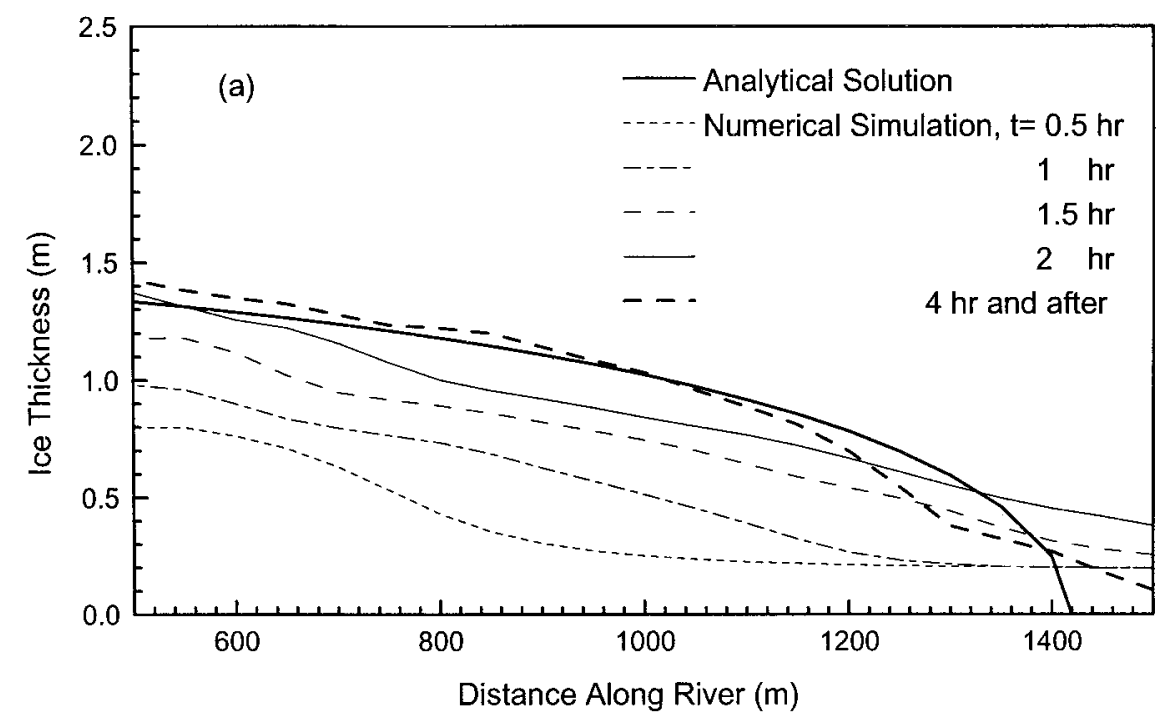

a. Simulated time-dependent evolution of ice jam profile.

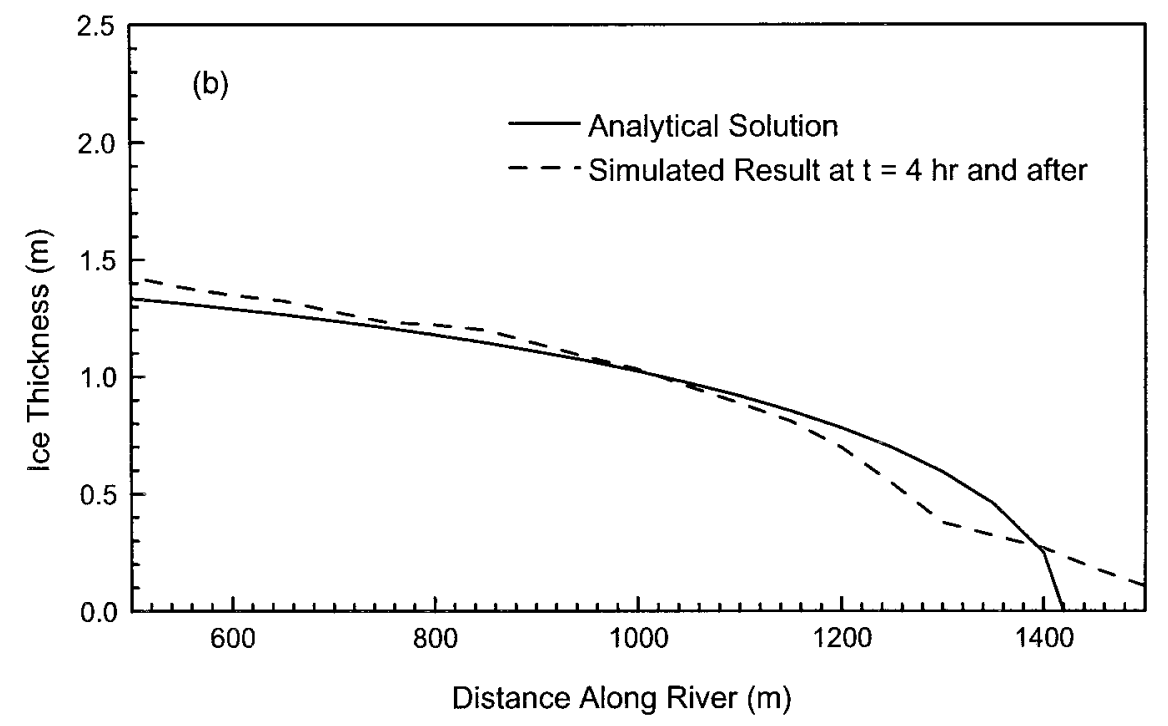

\section{b. Comparison of final jam profile with steady-state analytical solution.}

Figure 7. Comparison of simulated jam profiles and the analytical solution for the zero bank friction case.

The simulated result and analytical solution are compared in Figure 8. The simulated profile for $t \geq 4$ hours and the analytical solution are different because the ice momentum was neglected in the analytical solution. Figure 9 presents two-dimensional plots showing the development of the ice thickness distribution upstream of the boom.

Theoretically, the viscous-plastic constitutive law cannot simulate static conditions correctly. For very small strain rates, the viscosity becomes very large. In numerical computations, a limiting value for $\mu$ is often used. This approximation changes the constitutive relationship to a linear viscous law and the shear stress approaches zero when the strain rate approaches zero.
In this study, the constitutive law is modified for a small strain rate condition to avoid these problems.

In the simulation, critical values of $\sigma_{\mathrm{ij}}$ and $P$ for each ice parcel were determined as the following conditions are all satisfied: 1) ice parcel velocity is smaller than a small critical value of $0.001 \mathrm{~m} / \mathrm{s}, 2$ ) ice parcel velocity is smaller than the value in the previous time step, and 3) $\delta=\left|\dot{\varepsilon}_{1}-\dot{\varepsilon}_{2}\right|$ is smaller than a very small value $\delta_{\mathrm{c}}=1 \times 10^{-4} \mathrm{~s}^{-1}$. When these critical conditions are reached, the following approximation is introduced to calculate ice stresses for the particular ice parcel:

$$
\sigma_{\mathrm{ij}}=\sigma_{\mathrm{ijc}} \frac{P}{P_{\mathrm{c}}}
$$




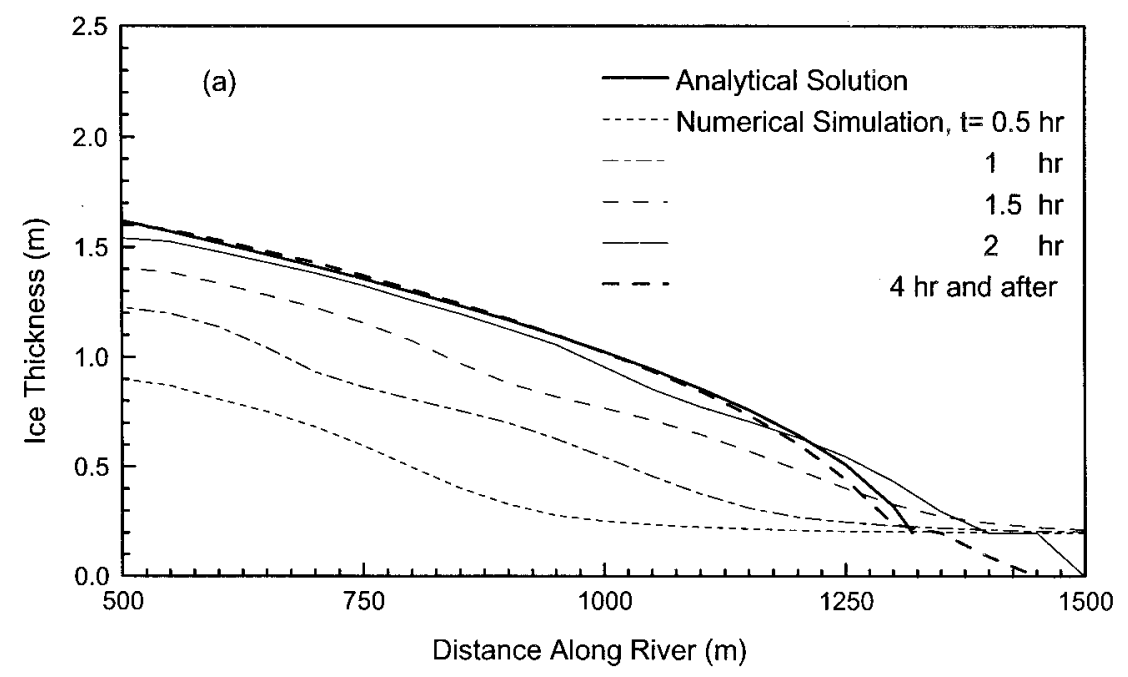

a. Simulated time-dependent evolution of ice jam profile.

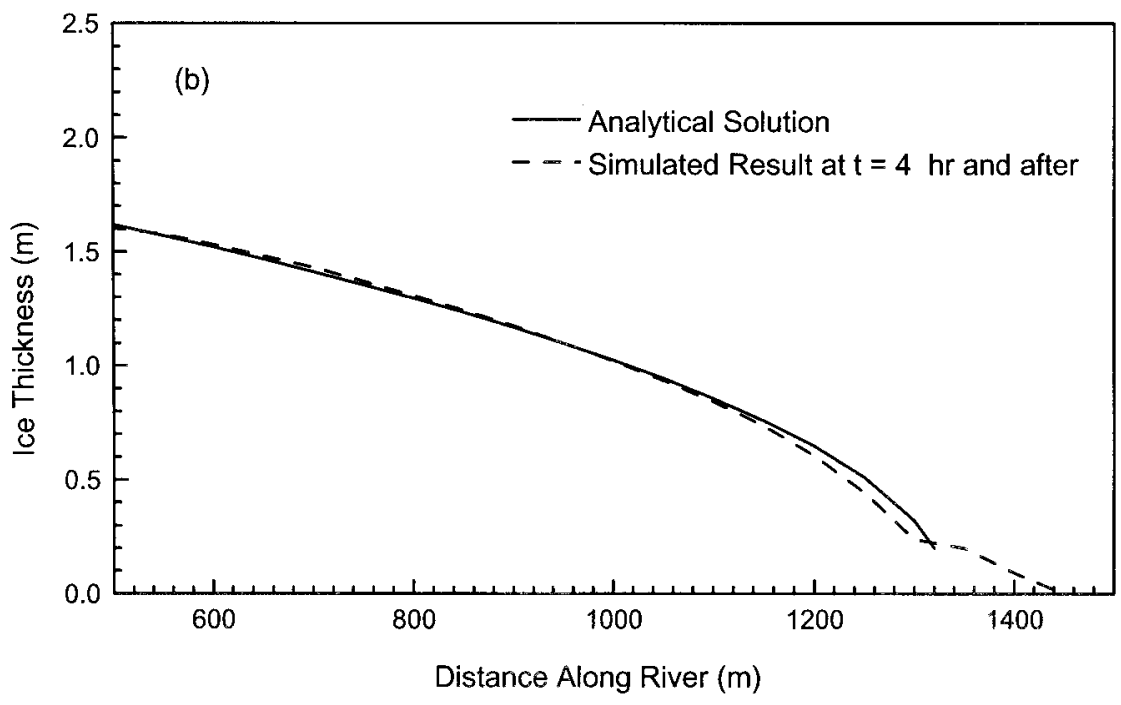

b. Comparison of final jam profile with steady-state analytical solution.

Figure 8. Comparison of simulated jam profiles with the analytical solution for the case with bank friction.

where $\sigma_{\mathrm{ijc}}$ and $P_{\mathrm{c}}$ are critical values of $\sigma_{\mathrm{ij}}$ and $P$, respectively. In addition, when the velocity of an ice parcel is less than $0.5 \mathrm{~mm} / \mathrm{s}$, the parcel is stopped. Using this method, we can simulated the static ice jam condition with the viscous-plastic constitutive law.

\section{Open water calibration for Missouri River}

The model is calibrated for the open water condition to determine the Manning's coefficient of the channel bed so that the model can correctly simulate the current velocity distribution and water surface slope. The detailed geometry survey data provided by Kenneth Balk \& Associates, Inc., cover the Missouri River from
RM 0 to 24, as well as the Mississippi River from St. Louis to the mouth of the Missouri (RM 187-195), with cross sections about $300 \mathrm{~m}$ apart. Tuthill* developed the stage-discharge relationships using HEC-2 simulations for the reach from the St. Louis gage up to about RM 30 on the Missouri River (see Fig. 1 for a map of the confluence area). The HEC-2 model was calibrated to flows in September 1994 at Hermann, Missouri, the corresponding observed water surface elevations, and average velocity from USGS stream

*Personal communication with A. Tuthill, CRREL, 1997. 

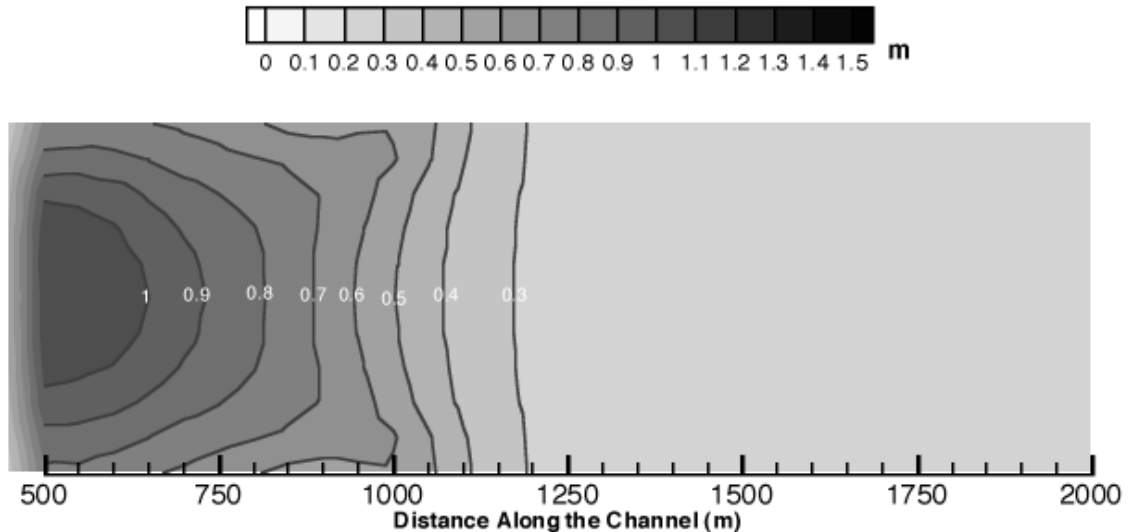

a. Hour 1.

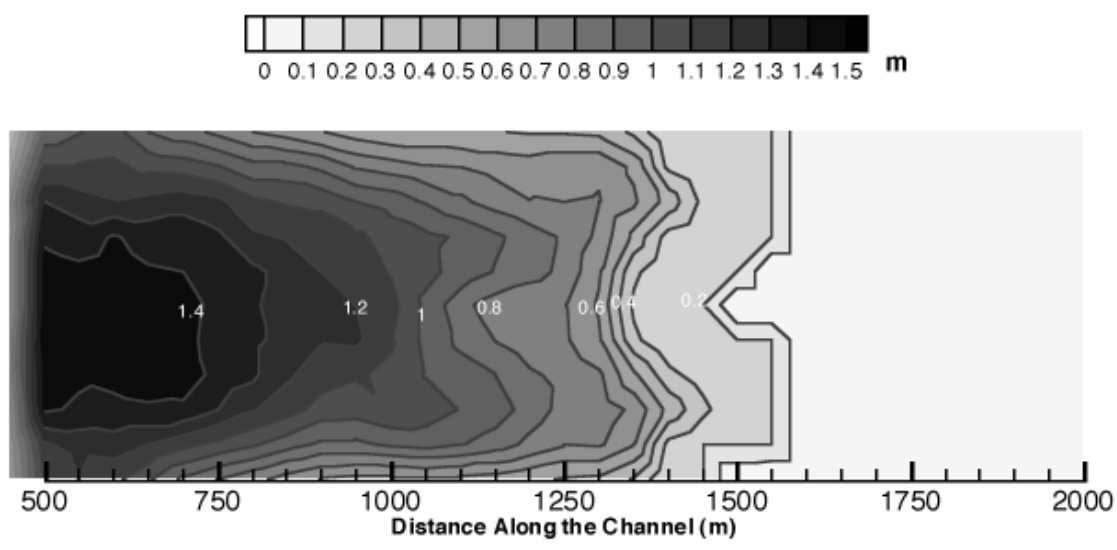

b. Hour 4.

Figure 9. Ice thickness distributions.

gaging data. The present hydrodynamic model is calibrated to the HEC-2 results.

In a one-dimensional study of ice jamming on the Missouri using the ICETHK model, Tuthill found two possible locations where an ice boom may be used: RM 16 and RM 8.2. For computational efficiency, two model domains are used for these two boom sites. Domain 1 covers RM 13-20 and domain 2 covers RM 5-13. The finite-element mesh and bed elevation for domain 1 are shown in Figure 10. Similar plots for domain 2 are shown in Figure 11. The two-dimensional model water surface profiles are compared to HEC-2 water levels in Figure 12. The Manning's coefficients for the bed are shown in Table 2.

\section{Simulation of the January 1977 Missouri River Ice Jam}

Manning's coefficients for the river bed were determined by the open water calibration in the last section. The Manning's coefficient for the ice cover had to be calibrated, and the internal friction angle of ice $\phi$ and the empirical constant $j$ in eq 37 had to be validated. The MRD ice data spread sheets for the January 1977 ice event give the daily position of the leading edge of a freezeup ice jam that progressed upstream during 1722 January 1977. Using an average flow of $650 \mathrm{~m}^{3} / \mathrm{s}$ $\left(23,000 \mathrm{ft}^{3} / \mathrm{s}\right), \phi=45^{\circ}, \mu_{2}=1.17$, and $n_{\mathrm{i}}=0.04$, the ICETHK model simulation, with the ice jam toe placed below the confluence at RM 193.8 of the Mississippi River, gives an average ice jam thickness of about 0.9 m (3ft) upstream of RM 8 on the Missouri River.* The ICETHK model is a one-dimensional steady-state model, which calculates the ice thickness profile of a wide-river jam based on an ice jam force balance that is similar to the model of Flato and Gerard (1986). Assuming an ice jam porosity of 0.4 , we determined the average ice discharge upstream of the jam to be about $13.5 \mathrm{~m}^{3} / \mathrm{s}\left(475 \mathrm{ft}^{3} / \mathrm{s}\right)$ to account for this observed upstream progression. Assuming a floe thickness of 0.15

*Personal communication with A. Tuthill, CRREL, 1997. 


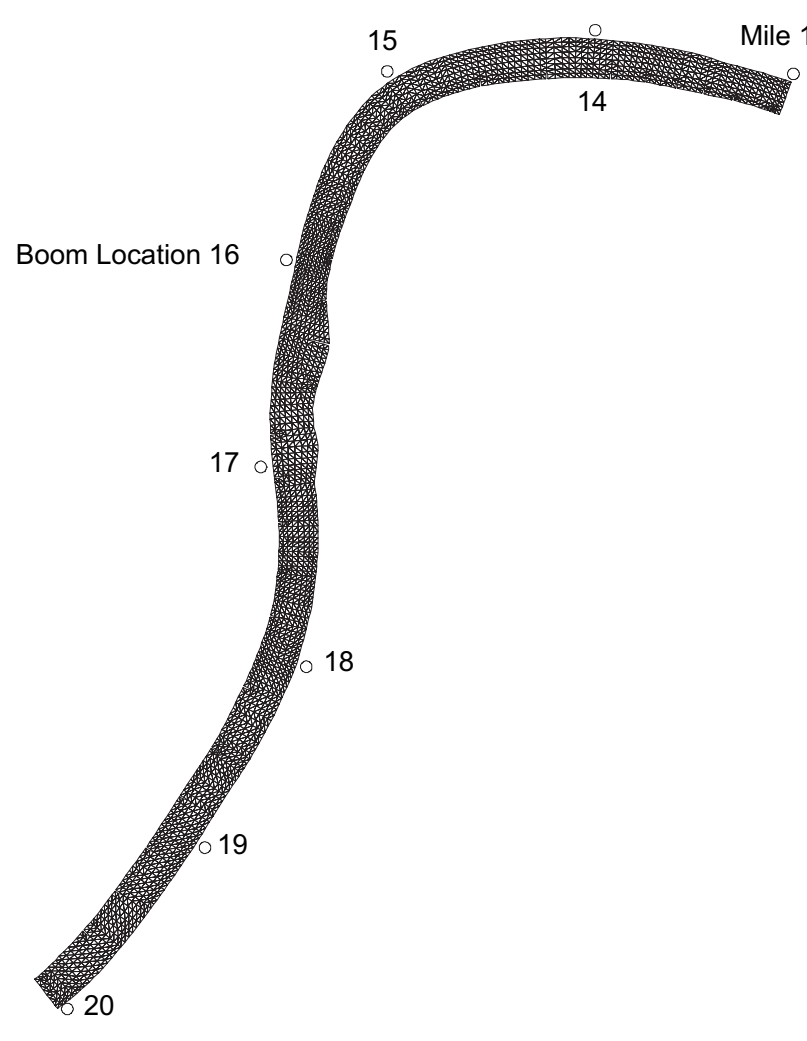

a. Finite-element mesh for RM 13-20.

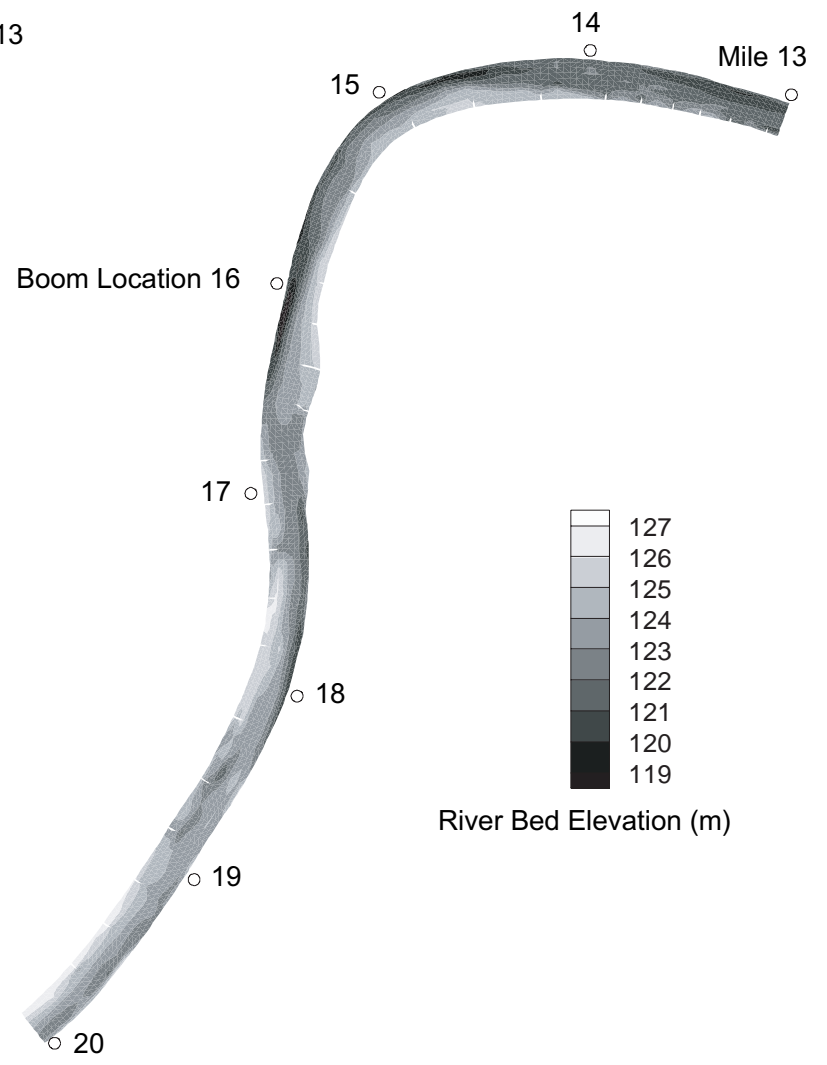

b. Bed elevation map for RM 13-20.

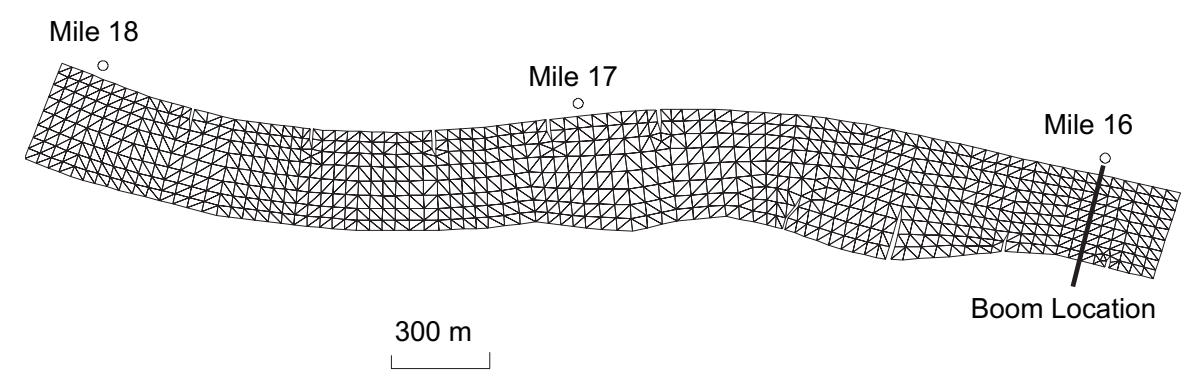

c. Finite-element mesh for RM 16-18.

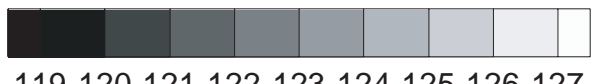

Mile 18

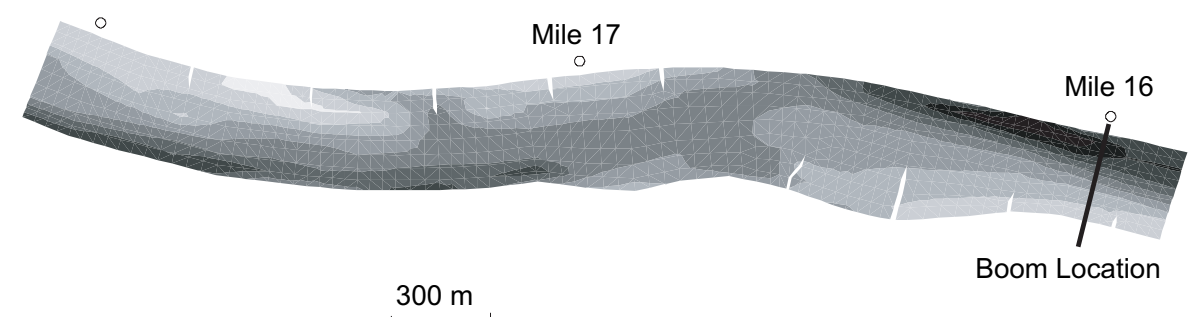

d. Bed elevation for RM 16-18.

Figure 10. Model domain 1. 


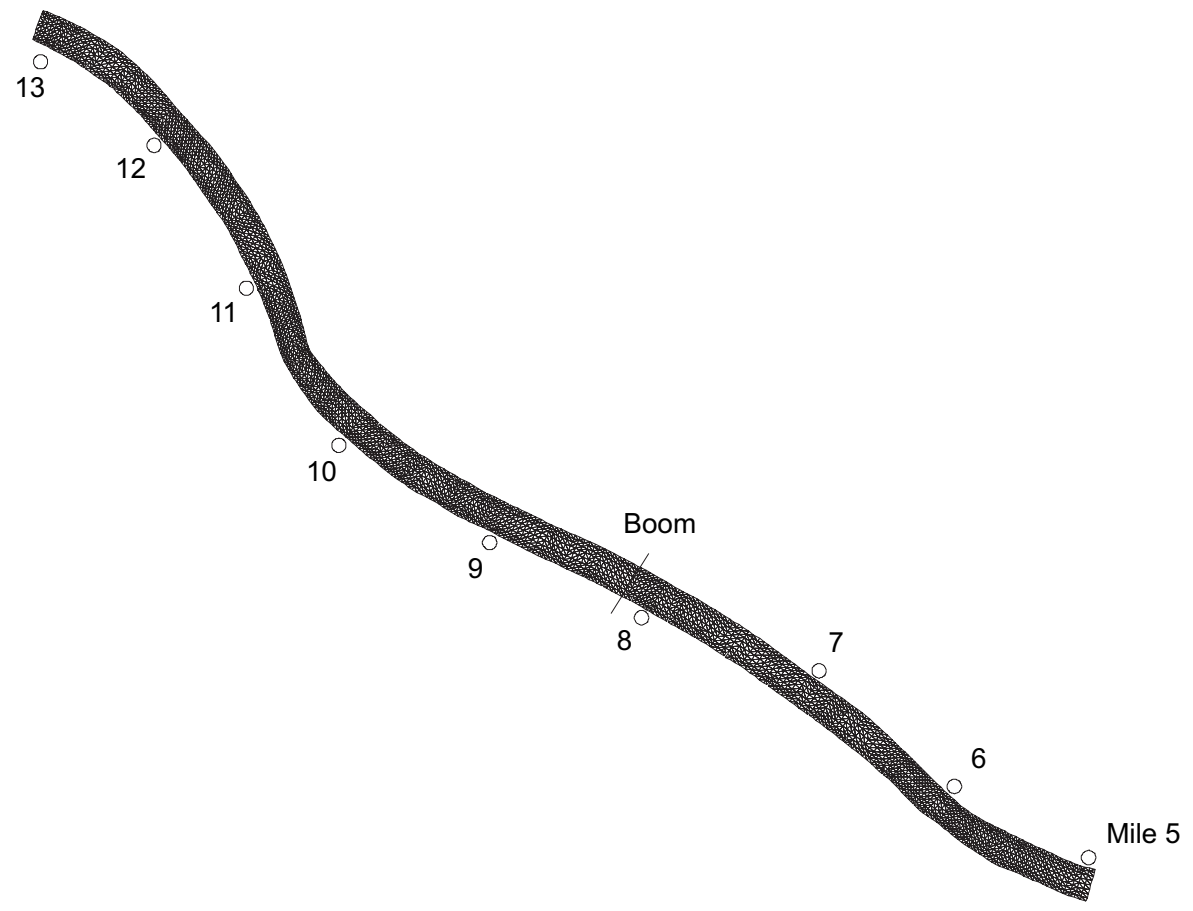

a. Finite-element mesh for RM 5-13.

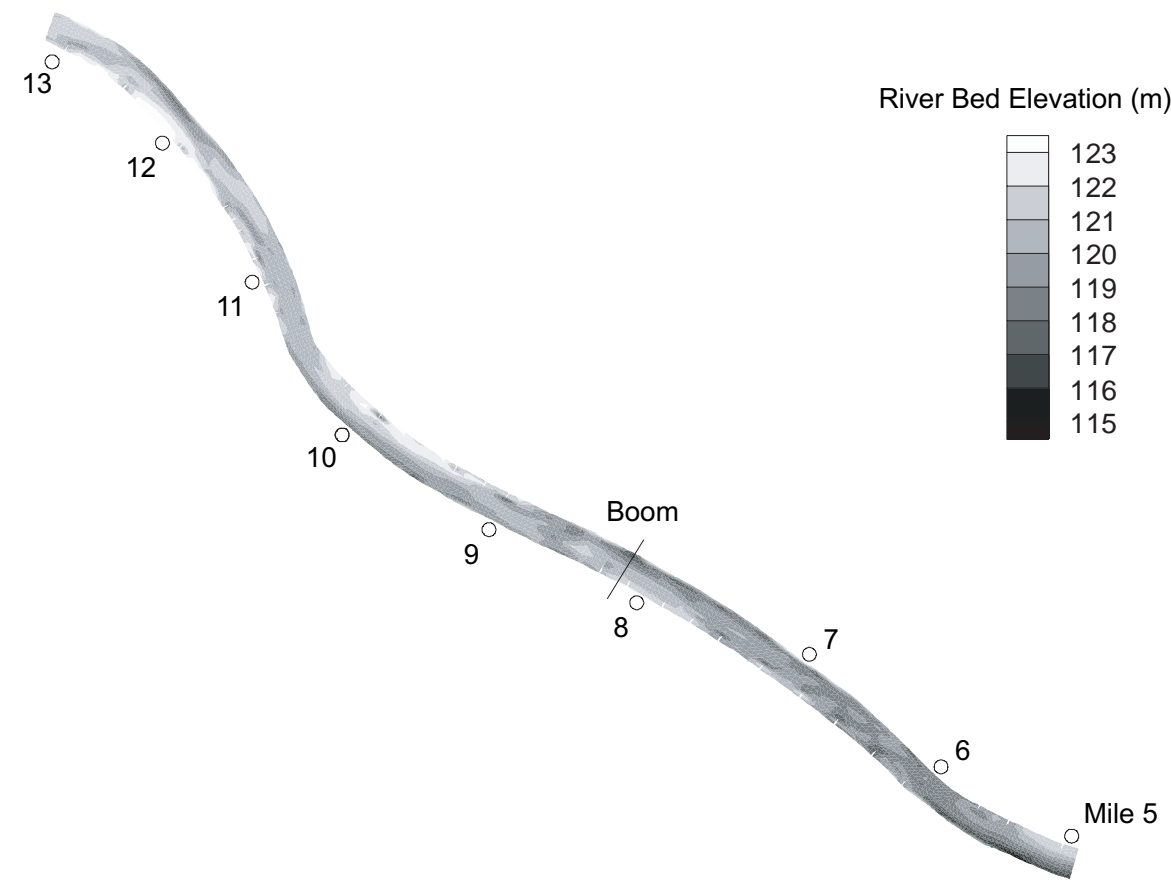

b. Bed elevation map RM 5-13.

Figure 11. Model domain 2. 


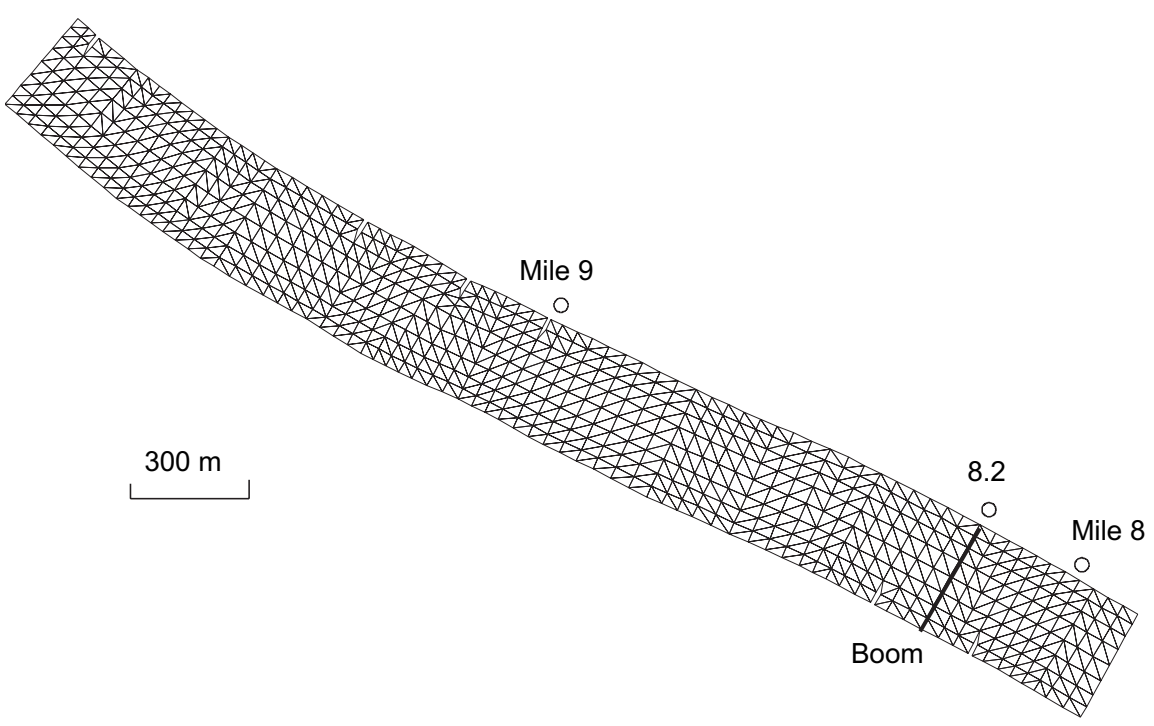

c. Finite-element mesh for RM 8-10.

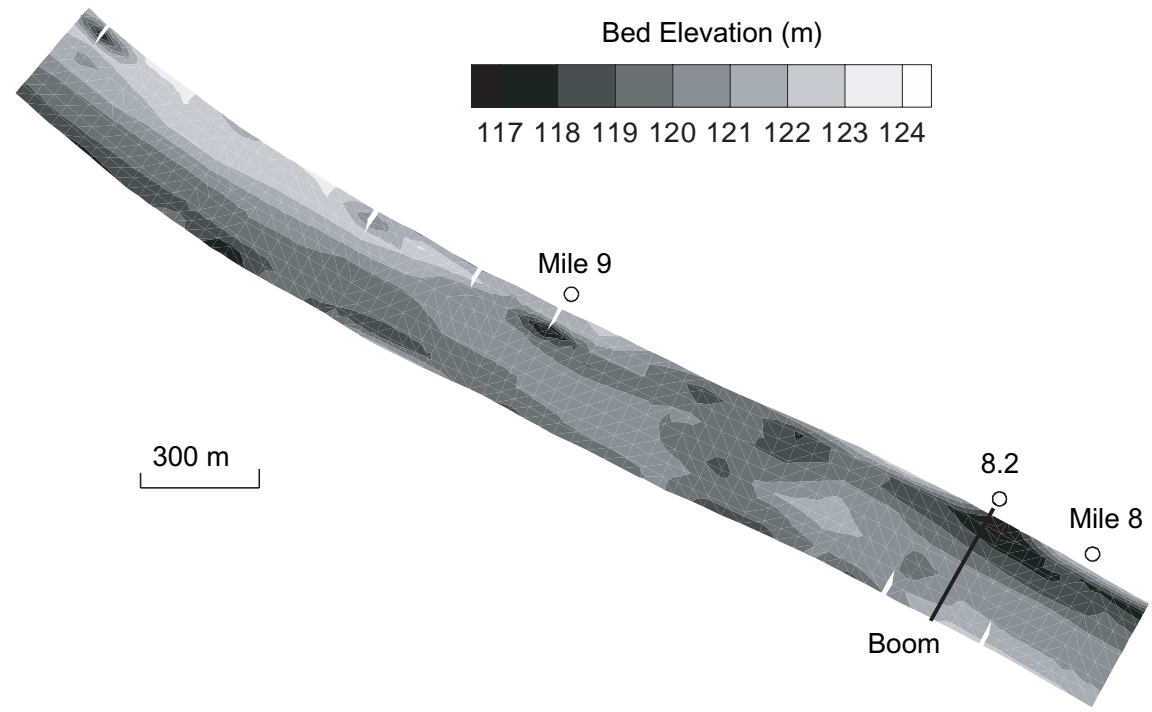

d. Bed elevation for RM 8-10.

Figure 11 (cont'd). 


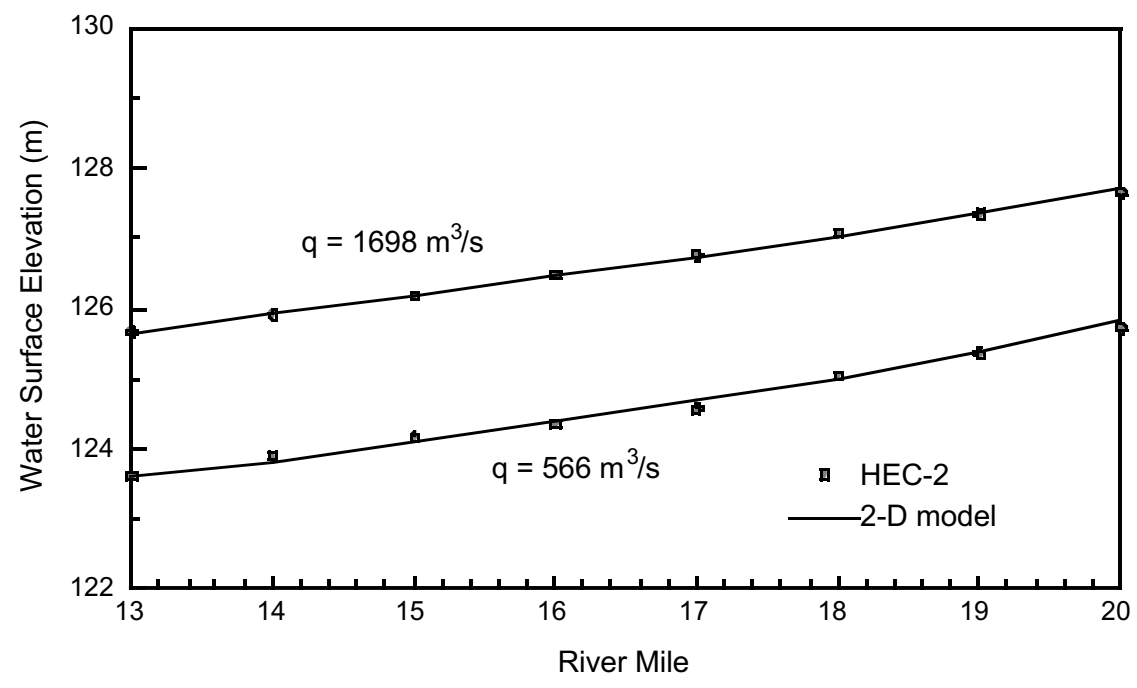

a. Domain 1 (RM 13-20).

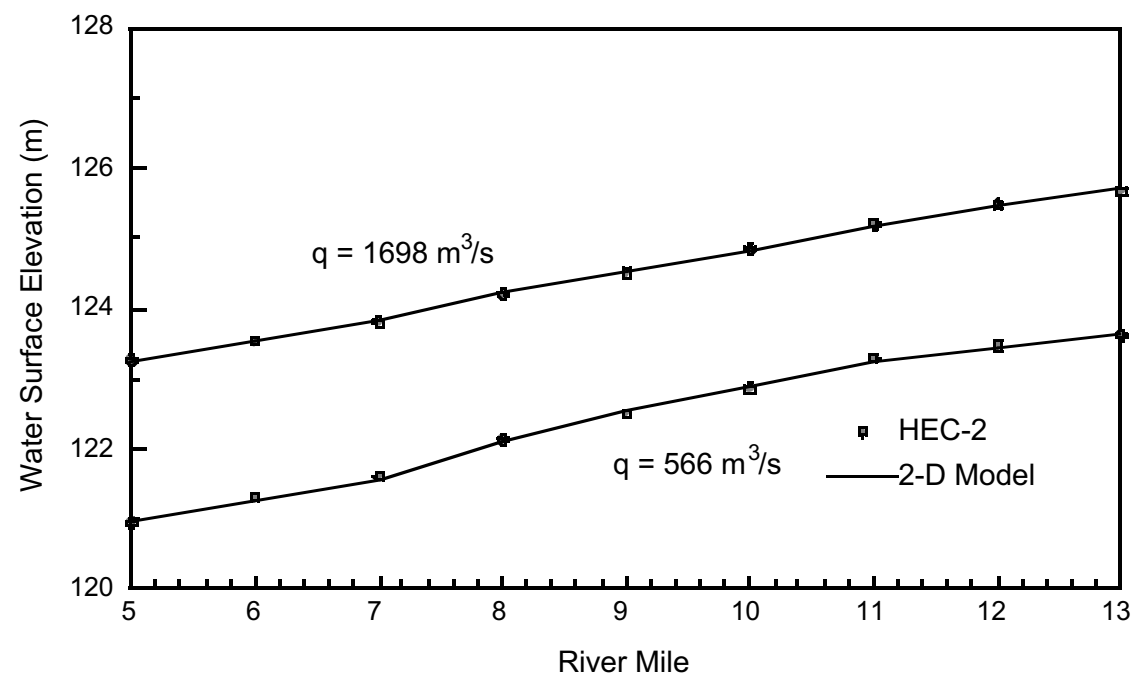

b. Domain 2 (RM 5-13).

Figure 12. Comparison of ice-free water surface profiles.

$\mathrm{m}(0.5 \mathrm{ft})$ and an ice velocity of $1.2 \mathrm{~m} / \mathrm{s}(4 \mathrm{ft} / \mathrm{s})$, we estimated the surface concentration of the moving pans and floes to be about $30 \%$. This estimate compares reasonably well with aerial photographs of moving ice at the mouth of the Missouri on 9 January 1979, 9

\begin{tabular}{|cc|}
\hline \multicolumn{2}{|c|}{ Table 2. Calibrated bed roughness. } \\
RM & Manning's $\mathrm{n}$ for bed \\
\hline $5-7$ & 0.022 \\
$7-9$ & 0.020 \\
$9-11$ & 0.015 \\
$11-13$ & 0.015 \\
$13-20$ & 0.019 \\
\hline
\end{tabular}

February 1989, and 16 December 1989. These photos showed surface ice concentrations of 20 to $30 \%$.* On the basis of this ice discharge estimate and a downstream water surface elevation estimated by the ICETHK model, the ice accumulations behind the booms at RM 16 in domain 1 and RM 8.2 in domain 2 were simulated by the present two-dimensional model.

\section{Simulation with a boom at RM 16}

The downstream boundary water level for domain 1 at RM 13 was obtained by making the simulated water level at boom location RM 16 the same as the ICETHK model result, which was $128 \mathrm{~m}$ (420 ft). The Manning's

*Personal communication with A. Tuthill, CRREL, 1997. 


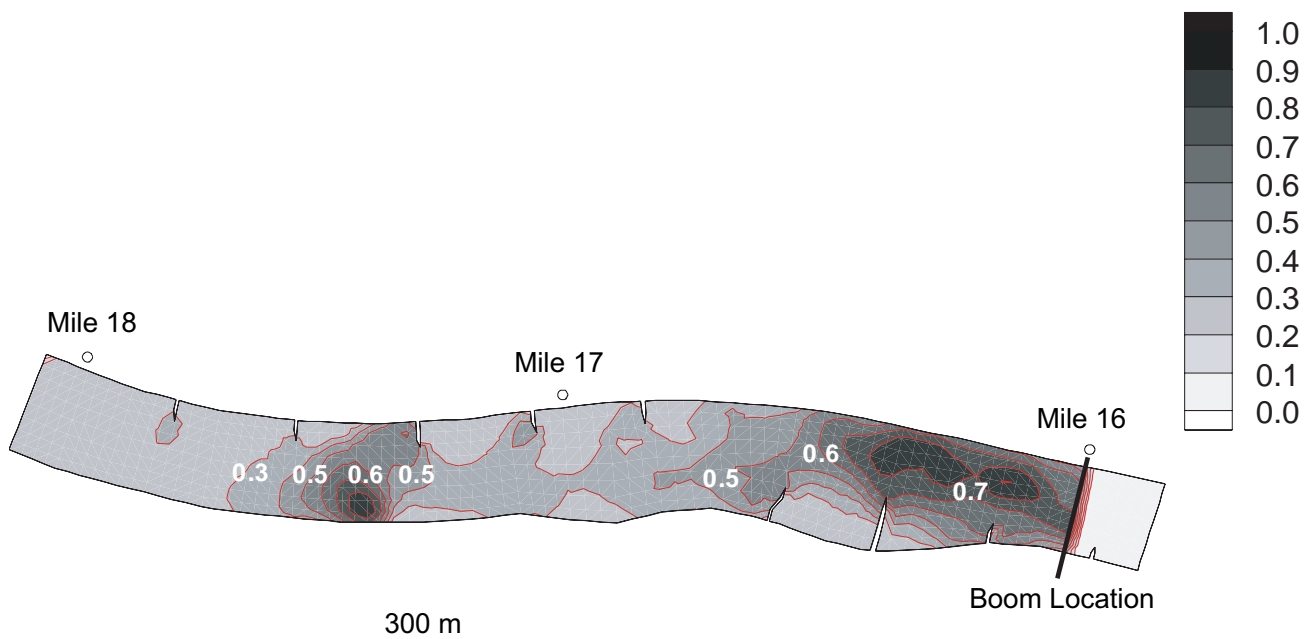

a. Hour 10.

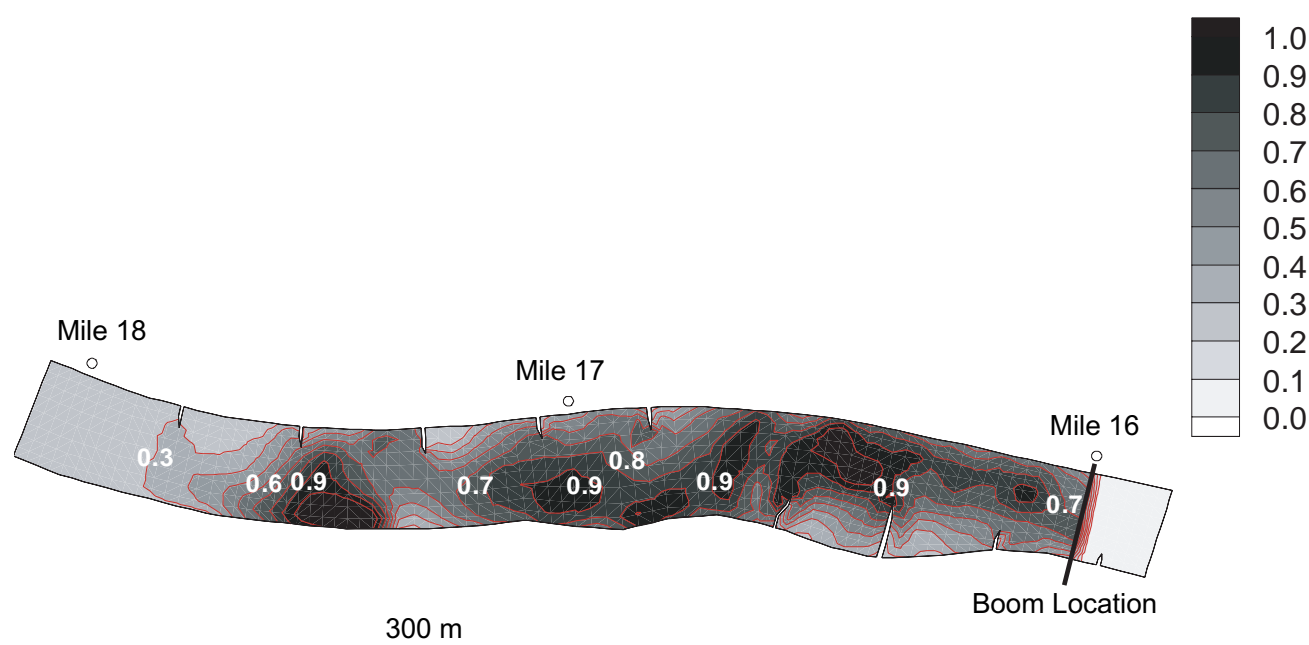

b. Hour 15.

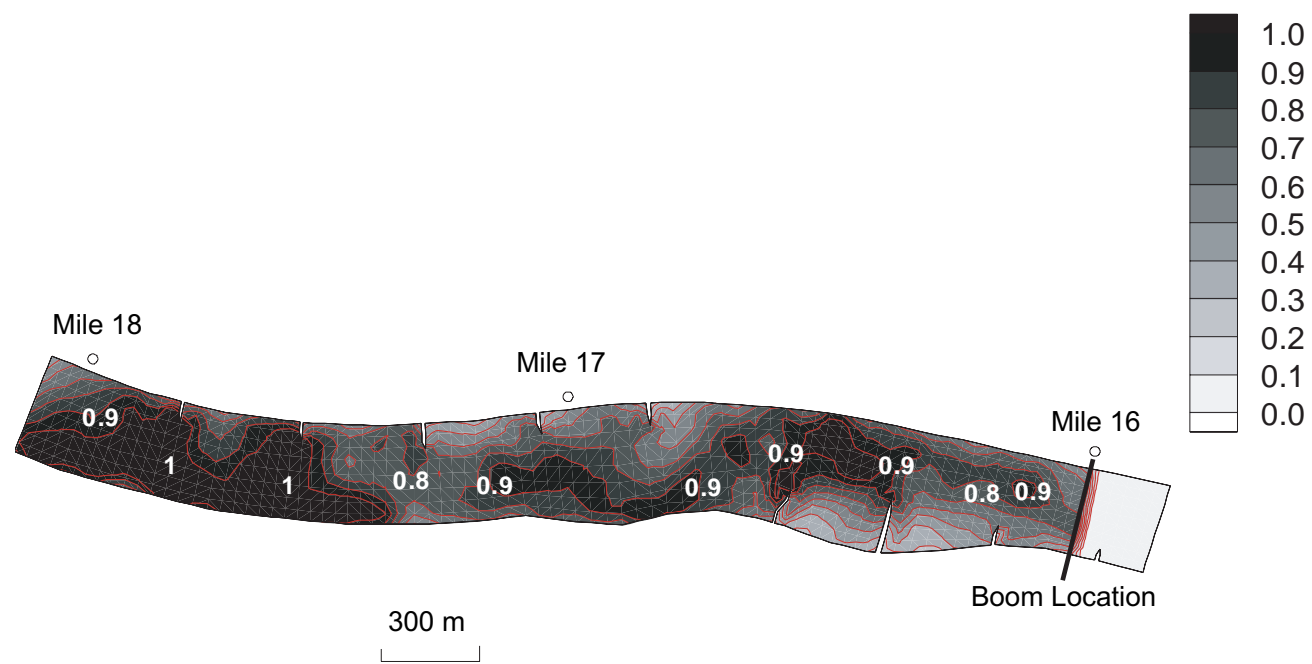

c. Hour 20.

Figure 13. Simulated ice thickness distribution behind the boom at RM 16. 
coefficient $n_{\mathrm{i}}$ is 0.02 for single ice layer and increases with the ice thickness (Shen and Chen 1992). The $n_{\mathrm{i}}$ value was limited to a maximum of 0.05 for multilayer ice. Water discharge was $650 \mathrm{~m}^{3} / \mathrm{s}\left(23,000 \mathrm{ft}^{3} / \mathrm{s}\right)$. At the upstream boundary, the ice concentration is set to be 0.45 in the main stream of the river, which gave an ice discharge of about $7.4 \mathrm{~m}^{3} / \mathrm{s}\left(260 \mathrm{ft}^{3} / \mathrm{s}\right)$ in the simulation.

The simulated ice thickness distributions at hours 10, 15, and 20 are shown in Figure 13. At hour 20 the simulated ice cover was about $3.2 \mathrm{~km}$ ( 2 miles) long, with a thickness in the $0.6-$ to $0.9-\mathrm{m}$ (2- to $3-\mathrm{ft})$ range.
In this case, the water level at the boom location was very high because of the assumption that an ice cover existed downstream of RM 13 at the start of the simulation. The simulated maximum water velocity near the boom was only $0.6 \mathrm{~m} / \mathrm{s}$ ( $2 \mathrm{ft} / \mathrm{s})$, and no ice passed the structure.

\section{Simulation with a boom at RM 8.2}

In the simulation done for domain 2 (RM 5-13), with a boom at RM 8.2, the downstream boundary water level at RM 5 of $124.36 \mathrm{~m}$ (408 ft) was obtained from the ICETHK simulated ice jam profile initiated at the

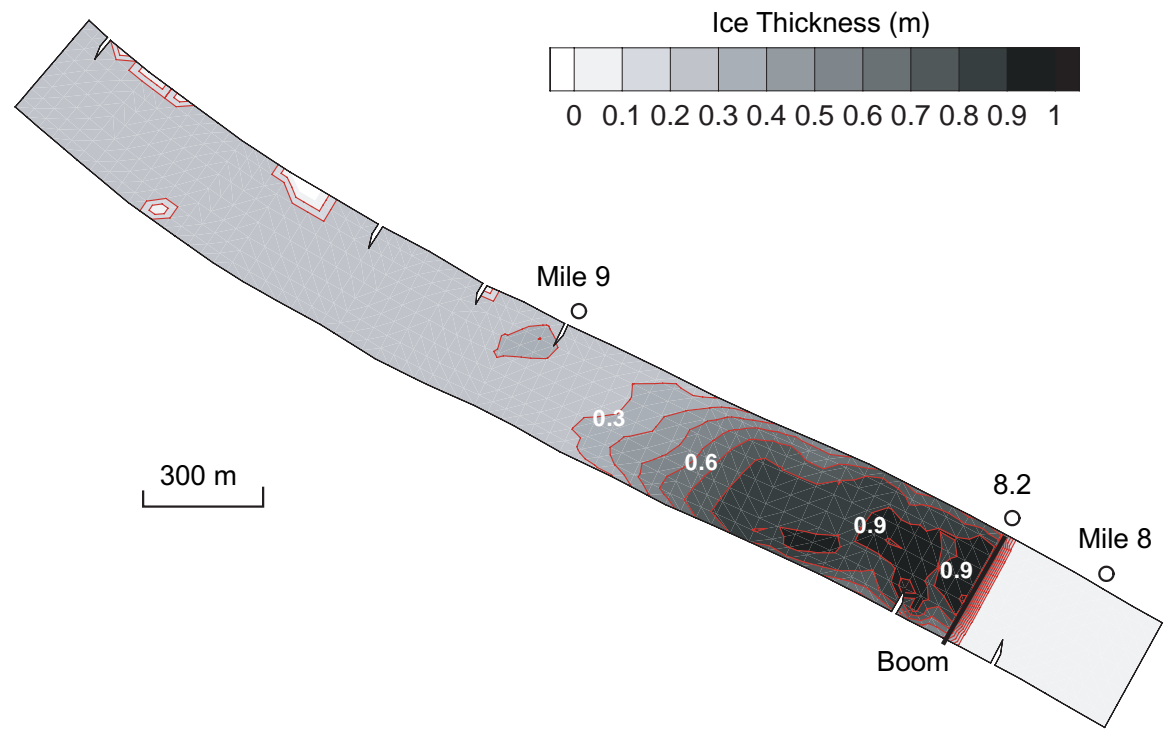

a. Hour 10.

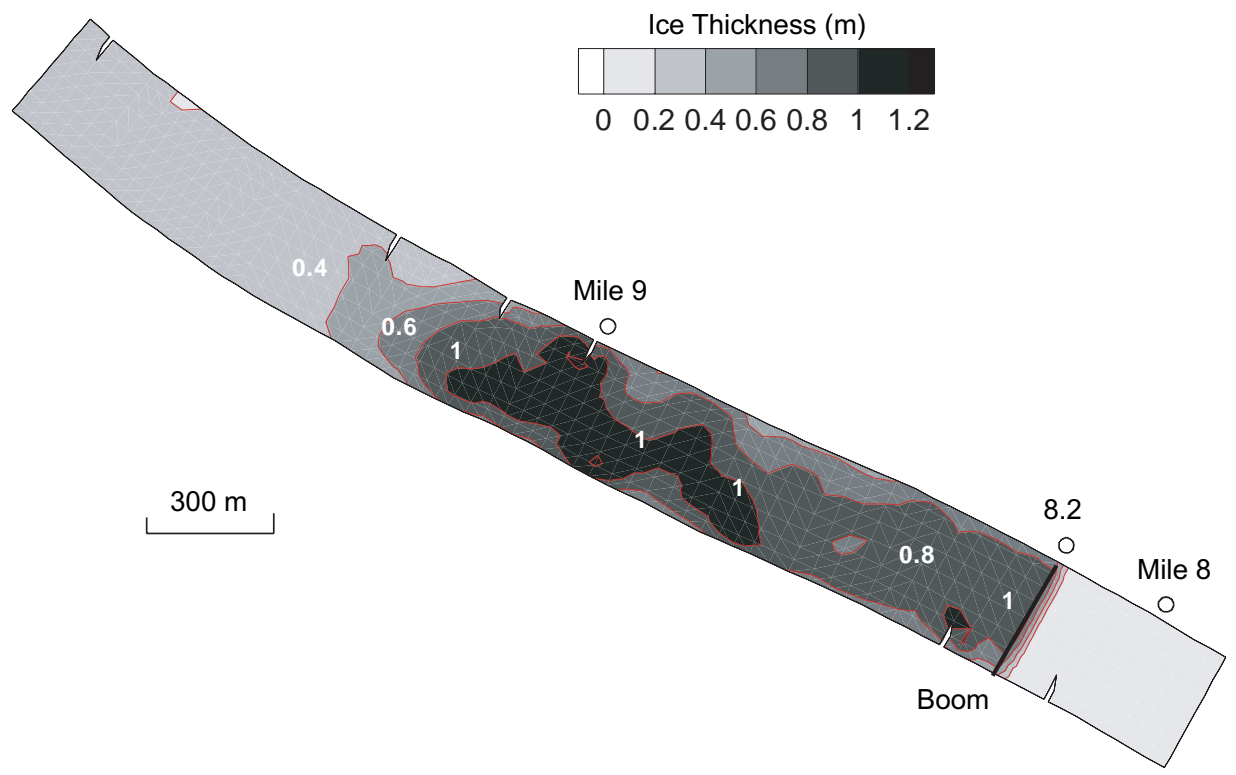

b. Hour 15.

Figure 14. Simulated ice thickness distribution behind the boom at RM 8.2. 


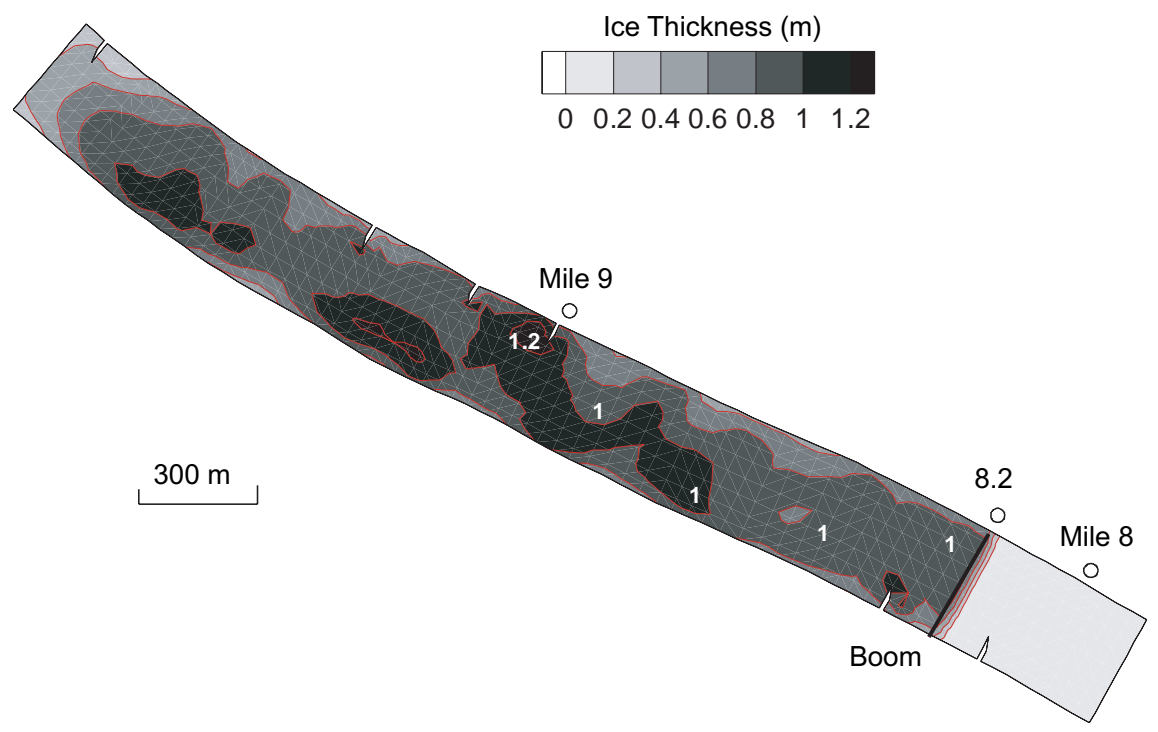

c. Hour 20.

Figure 14 (cont'd).

confluence. The water level at the boom location is $125.27 \mathrm{~m}(411 \mathrm{ft})$. Water discharge is $650 \mathrm{~m}^{3} / \mathrm{s}(23,000$ $\left.\mathrm{ft}^{3} / \mathrm{s}\right)$, the same as in the previous case. Ice discharge is about $6.8 \mathrm{~m}^{3} / \mathrm{s}\left(240 \mathrm{ft}^{3} / \mathrm{s}\right)$.

Since the water velocity near the boom is less than $0.6 \mathrm{~m} / \mathrm{s}(2 \mathrm{ft} / \mathrm{s})$, ice stops at the boom, and an ice accumulation develops upstream.

The simulated ice thickness distributions at hours 10, 15, and 20 are shown in Figure 14. The results show that the ice cover length is about $3.2 \mathrm{~km}$ ( 2 miles) at hour 20, and the thickness was in the range of 0.9 to $1.2 \mathrm{~m} \mathrm{(3}$ to $4 \mathrm{ft}$ ), similar to the ICETHK-calculated ice thickness.

\section{ASSESSMENT OF ICE BOOM ALTERNATIVES}

The calibrated model was used to further assess the effectiveness of ice boom alternatives. Simulation results are presented here.

\section{$100 \%$ Effective ice booms normal to flow direction}

Two simulations were carried out with a $100 \%$ effective ice boom. Limiting conditions for ice accumulation behind the boom were not imposed in these simulations. The initial condition in the first simulation for domain 1 (RM 13-20), with the boom at RM 16, was an open water, steady-state, ice-free flow at a discharge of $566 \mathrm{~m}^{3} / \mathrm{s}\left(20,000 \mathrm{ft}^{3} / \mathrm{s}\right)$. The downstream boundary condition at RM 13 was a water surface elevation of $123.6 \mathrm{~m}$ (405.6 ft). Upstream boundary conditions were a constant water discharge of $566 \mathrm{~m}^{3} / \mathrm{s}\left(20,000 \mathrm{ft}^{3} / \mathrm{s}\right)$ and an ice discharge of 11.3 $\mathrm{m}^{3} / \mathrm{s}\left(400 \mathrm{ft}^{3} / \mathrm{s}\right)$. In the second simulation, for domain 2 (RM 5-13), the boom was placed at RM 8.2, above the Lewis Bridge. The same water and ice discharge conditions as in the first simulation were used. The downstream water level at RM 5 was 120.95 m (396.8 $\mathrm{ft}$ ). The goals of these simulations were to see how the ice jams and boom loads would develop if the booms were $100 \%$ effective.

The simulated results showed that the ice thickness at the boom locations was high and that the ice grounded across most of the channel width near the boom, as shown in Figures 15 and 16. The simulated jams increased upstream water levels significantly, as shown in Figure 17. Upstream of the toe area, the ice thickness decreased to about 0.9 to $1.2 \mathrm{~m}$ for the boom located at RM 8.2, and 0.9 to $1.8 \mathrm{~m}$ for the boom located at RM 16.

The loads on the booms are shown in Figure 18. The maximum load per unit width was about 40 to 50 $\mathrm{kN} / \mathrm{m}$. The results showed that the boom loads leveled off as the jam extended upstream. This was attributable to the grounding of the jam, as well as the increase in bank resistance as the jam progressed further upstream. In domain 1, because of the low water discharge, the high bed elevation causes the right one-third of the channel width to have no flow. 


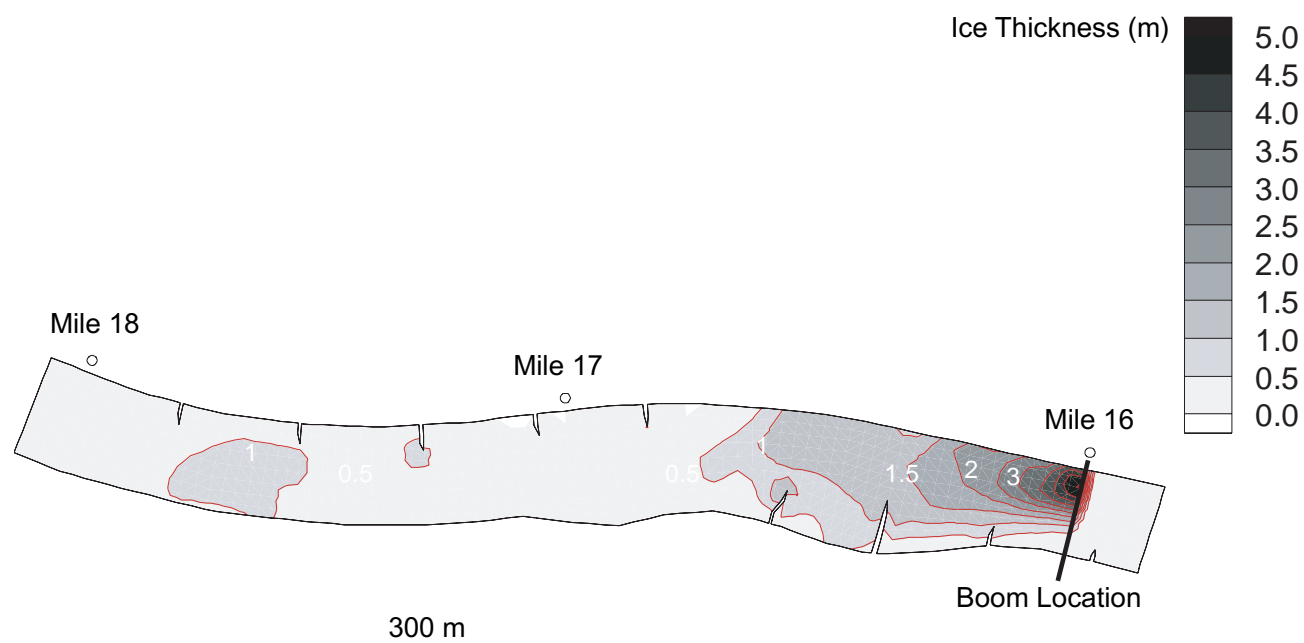

a. Hour 8 .

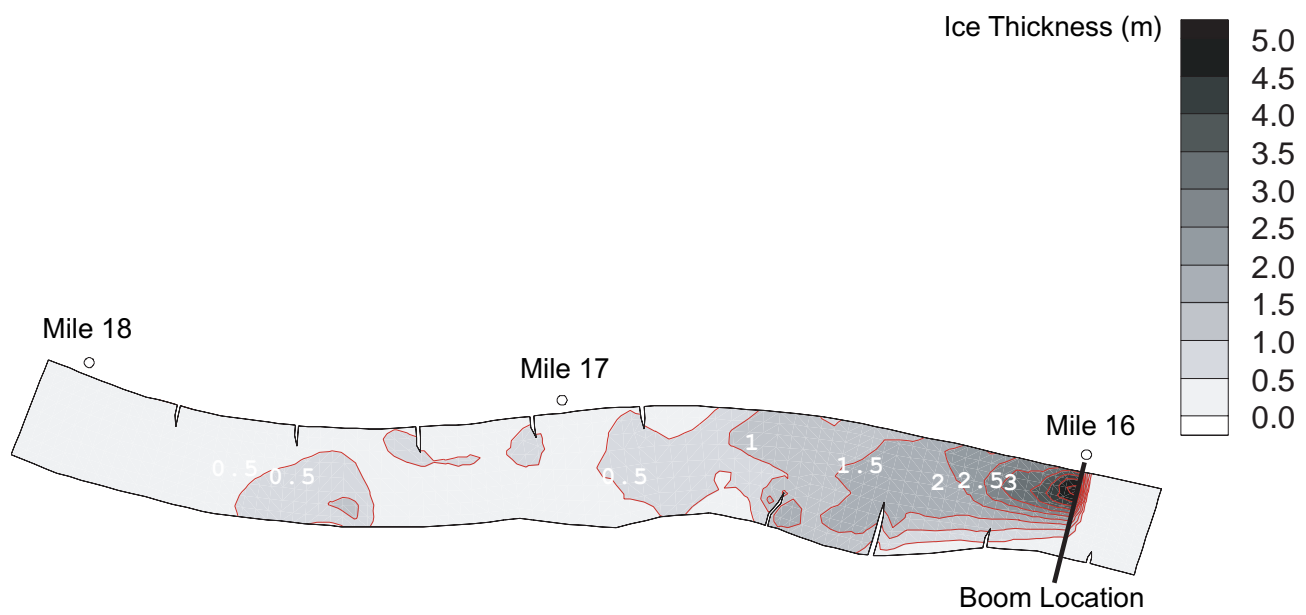

$300 \mathrm{~m}$

b. Hour 10.

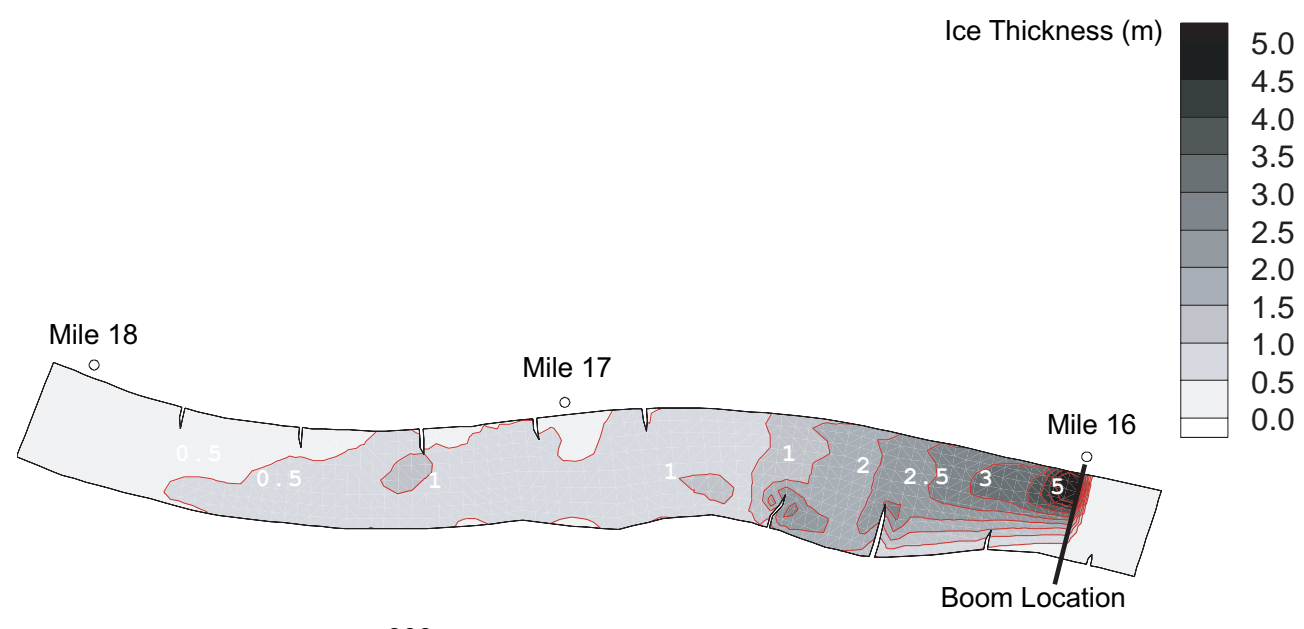

$300 \mathrm{~m}$

c. Hour 14.

Figure 15. Simulated ice thickness distribution behind the 100\% effective boom at RM 16. 

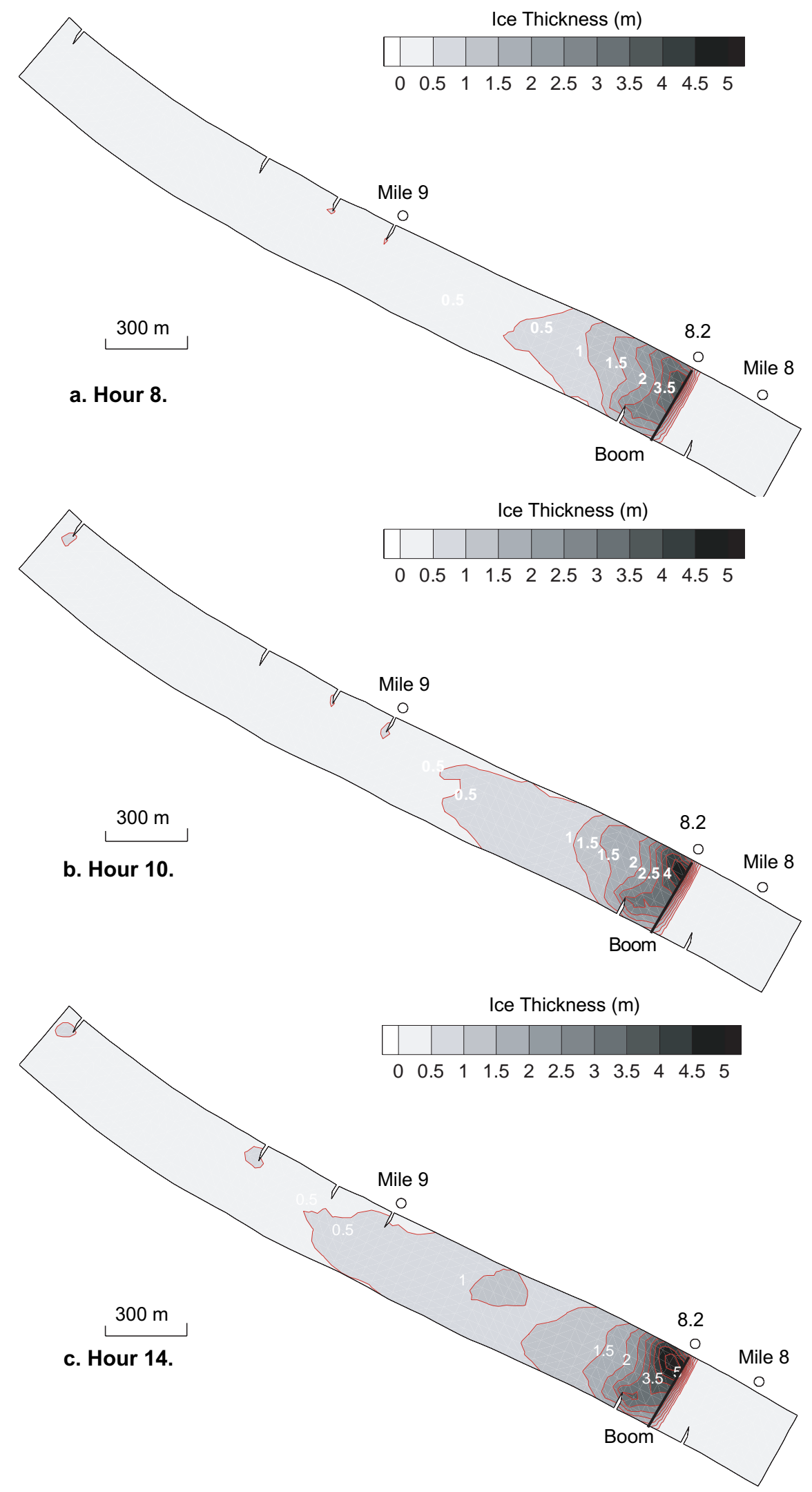

b. Hour 10.

Figure 16. Simulated ice thickness distribution behind the $100 \%$ effective boom at RM 8.2. 


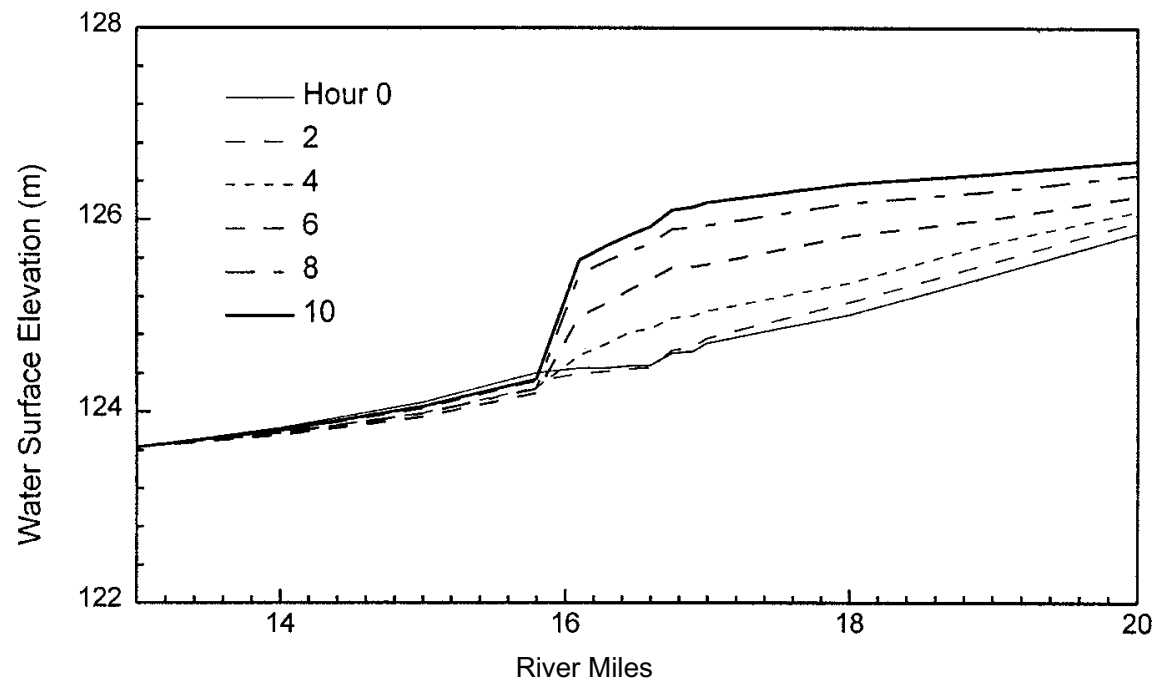

a. For the boom at RM 16.

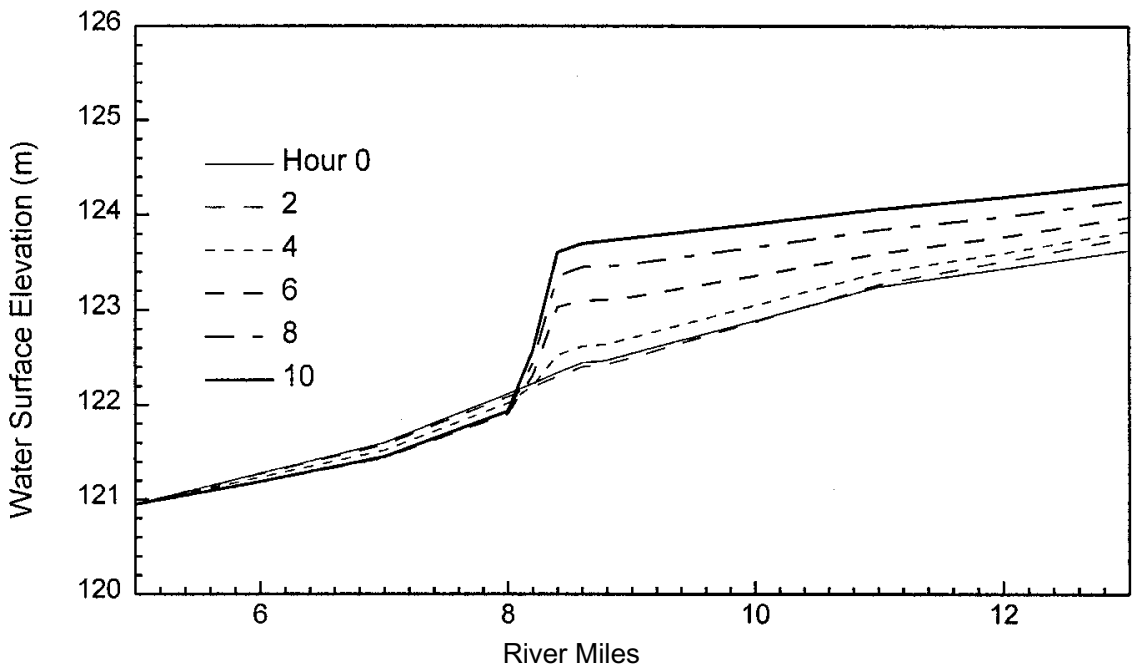

b. For the boom at RM 8.2.

Figure 17. Water surface profiles.

\section{Slant-oriented boom}

As discussed earlier, when the open water velocity approaches $0.7 \mathrm{~m} / \mathrm{s}$, the ice pans and floes approaching the boom will underturn and flow downstream, rendering the boom ineffective. Upstream of the backwater effect of the confluence, the water velocity in the lower Missouri River is typically above the threshold for ice retention by conventional means. Even at the extremely low flow of $566 \mathrm{~m}^{3} / \mathrm{s}\left(20,000 \mathrm{ft}^{3} / \mathrm{s}\right)$, velocity is in the range of $0.75-0.9 \mathrm{~m} / \mathrm{s}$. Specially designed booms may be able to form an ice cover under these high velocity conditions, however. For example, a simulation with a slant-oriented boom, instead of a boom normal to the flow, is shown in Figure 19. The boom is placed at RM 16 at an angle of about $45^{\circ}$ to the flow. This alignment reduces the velocity component normal to the boom to $70 \%$ of the longitudinal velocity component. 


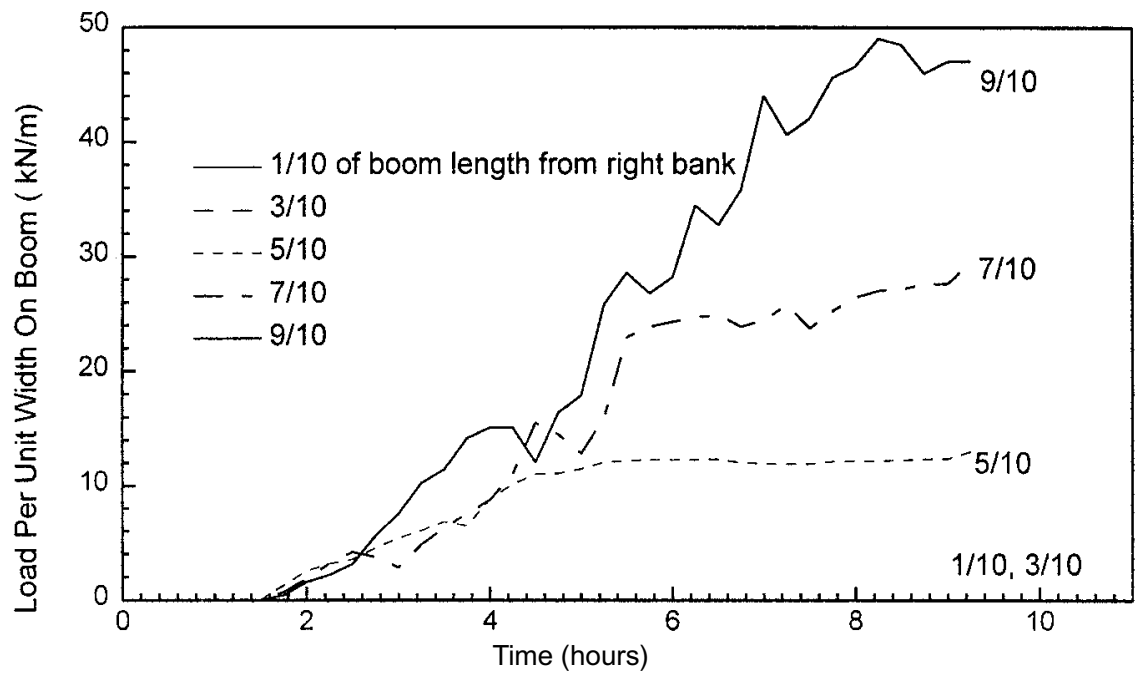

a. At RM 16.

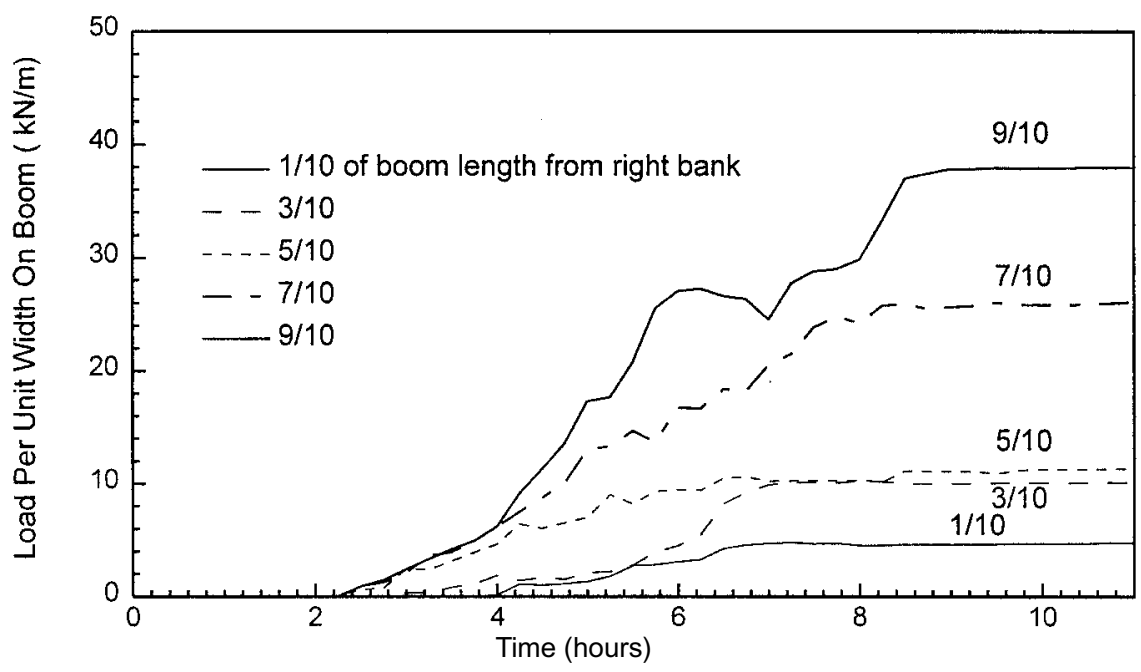

b. At RM 8.2.

Figure 18. Simulated load distribution on the boom.

In the simulation, as the ice parcels reached the boom, they were not entrained underneath but moved along the boom to accumulate in the shallow area near the shore, initiating progression upstream. With the increase in ice jam thickness, the water velocity underneath the ice cover increases as well. The critical erosion velocity of $1.5 \mathrm{~m} / \mathrm{s}$ was exceeded at the toe of the jam and ice started to be transported downstream. This prevented the cover from progressing further upstream.

\section{SUMMARY}

In this study a two-dimensional numerical model for simulating ice transport and accumulation behind river ice booms was developed. The model considered the dynamics of surface ice transport in the river, coupled with the hydrodynamics of the flow. The Lagrangian discrete-parcel method with smoothed particle hydrodynamics was used to simulate the ice dynamics, and a finite-element method was used to 


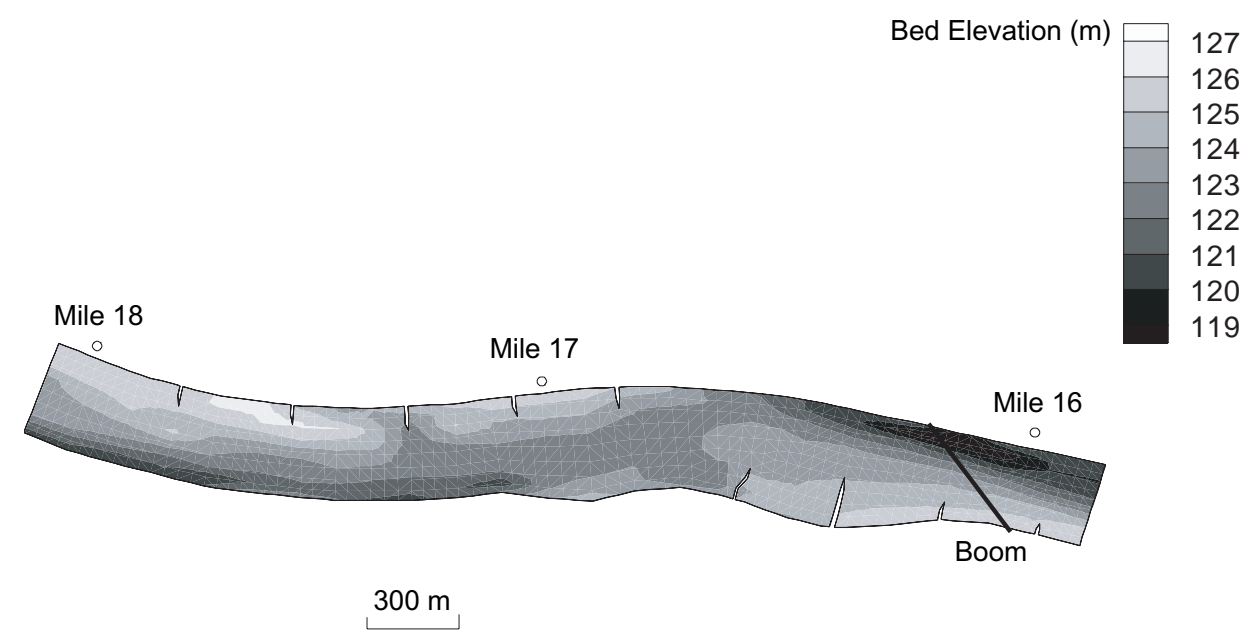

Figure 19. Bed elevation in the vicinity of the slant-oriented boom at RM 16.

solve the hydrodynamic equations. Ice entrainment at the boom and the leading edge of the ice accumulation, erosion of ice on the underside of the ice accumulation, and the limiting ice boom load for ice retention were considered. The model was verified with analytical solutions for idealized ice jams in rectangular channels, and calibrated to an ice jam that progressed up into the lower Missouri River from the middle Mississippi River during January 1977. The calibrated model was then used to study the feasibility of using ice booms to retain the ice in the lower Missouri River to reduce the jamming potential in the Mississippi River at the Missouri-Mississippi confluence and the middle Mississippi River.

Numerical simulations were made with a boom located at RM 16 or RM 8.2, the two most favorable locations for an ice boom. Table 3 summarizes the simulation results. In the first group of simulations,

\begin{tabular}{|c|c|c|c|c|c|c|}
\hline & & Table 3 & ummary & of simulation & results. & \\
\hline $\begin{array}{l}\text { Simulation } \\
\text { cases }\end{array}$ & $\begin{array}{l}\text { Water } \\
\text { discharge } \\
\left(\mathrm{m}^{3} / \mathrm{s}\right)\end{array}$ & $\begin{array}{c}\text { Ice } \\
\text { discharge } \\
\left(\mathrm{m}^{3} / \mathrm{s}\right)\end{array}$ & $\begin{array}{l}\text { Model } \\
\text { domain } \\
(R M)\end{array}$ & $\begin{array}{l}\text { Water level at } \\
\text { downstream } \\
\text { boundary }\end{array}$ & $\begin{array}{l}\text { Boom } \\
\text { location } \\
\text { (RM) }\end{array}$ & Comments \\
\hline \multirow[t]{2}{*}{$\begin{array}{l}\text { 1. Simulation for } \\
\text { Jan. } 1977 \text { jam } \\
\text { event }\end{array}$} & 650 & 7.36 & $13-20$ & 127.10 & 16 & $\begin{array}{l}\text { High downstream water surface } \\
\text { elevation attributable to the } \\
\text { presence of downstream ice jam. }\end{array}$ \\
\hline & 650 & 6.79 & $5-13$ & 124.36 & 8.2 & $\begin{array}{l}\text { Boom is effective. } t_{\mathrm{i}}=0.6-1.2 \mathrm{~m} \text {, } \\
\text { similar to ICETHK result. }\end{array}$ \\
\hline \multirow[t]{2}{*}{$\begin{array}{l}\text { 2. } 100 \% \text { effective } \\
\text { booms }\end{array}$} & 566 & 11.32 & $13-20$ & 123.63 & 16 & $\begin{array}{l}\text { With normal open water } \\
\text { conditions, downstream water } \\
\text { levels are much lower than in the } \\
\text { two cases above. }\end{array}$ \\
\hline & 566 & 11.32 & $5-13$ & 120.94 & 8.2 & $\begin{array}{l}\text { Ice partially grounded near the } \\
\text { boom. Boom loads as high as } 40 \\
\text { to } 50 \mathrm{kN} / \mathrm{m} \text {. }\end{array}$ \\
\hline $\begin{array}{l}\text { 3. Boom oriented } \\
\text { at } 45^{\circ} \text { to the flow }\end{array}$ & 566 & 11.32 & $13-20$ & 123.63 & 16 & $\begin{array}{l}\text { The boom may stop ice floes, but } \\
\text { erosion and entrainment limit } \\
\text { upstream progression. }\end{array}$ \\
\hline
\end{tabular}


water levels at the downstream boundary were assumed to be the same as those during the January 1977 ice jam, which extended from RM 193.8 of the Mississippi River to upstream of the boom locations. The ice and water discharges of the January 1977 ice jam were also used. These simulations showed that the boom could be effective at both locations. In the second group of simulations, an initial open water condition, with a low river discharge of $566 \mathrm{~m}^{3} / \mathrm{s}$, was assumed. The ice booms were assumed to be $100 \%$ effective, i.e., the limiting conditions for ice accumulation behind the boom were not imposed. These simulations showed that the lower downstream water levels of the open water condition resulted in partial grounding of ice in the vicinity of the booms. The boom loads were not uniform across the width, and leveled off as the ice cover extended upstream. The ice loads on the booms reached very high values, ranging from 40 to $50 \mathrm{kN} / \mathrm{m}$. Since the results of the second group of simulations showed that the flow velocity could exceed the entrainment velocity, an additional simulation was made with a boom oriented at an angle of $45^{\circ}$ to the main flow direction. This reduced the normal velocity of ice floes approaching the boom, and the ice was stopped at the boom. However, as the ice accumulation thickened behind the boom, the critical undercover erosion velocity was exceeded and the cover progression was halted.

Before the present study, ice retention behind booms was considered to be marginally possible, based on existing critical water velocity and Froude number criteria. The one-dimensional steady-state ice jam model ICETHK predicted that a stable ice accumulation was possible, but the model was unable to address dynamic processes. During problem ice years on the middle Mississippi River, the average Missouri River discharge is about $850 \mathrm{~m}^{3} / \mathrm{s}\left(30,000 \mathrm{ft}^{3} / \mathrm{s}\right)$. Two-dimensional simulations at the two most favorable sites (RM 8.2 and 16) carried out here found that ice retention behind booms is unfeasible even at a much lower discharge of $566 \mathrm{~m}^{3} / \mathrm{s}\left(20,000 \mathrm{ft}^{3} / \mathrm{s}\right)$, unless a specially designed boom with high ice retention capacity can be developed. The two-dimensional dynamic ice transport model proved to be a valuable tool for addressing important design issues that could not be answered by conventional methods.

\section{LITERATURE CITED}

Ashton, G.D. (1974) Froude criterion for ice-block stability. Journal of Glaciology, 13(68): 309-313.

Beltaos, S. (1983) River ice jam: Theory, case studies, and applications. Journal of Hydraulics Engineering, ASCE, 109(10): 1338-1359.
Beltaos, S. (1995) Ricer Ice Jams. Water Resources Publication, LLC.

Beltaos, S. (1993a) Flow through breakup jams. In Proceedings, 11th Canadian hydrotechnical Conference, Fredericton, N.B., June, pp. 643-652.

Beltaos, S. (1993b) Numerical computation of river ice jams. Canadian Journal of Civil Engineering, 20(1): 88-99.

Beltaos, S., and J. Wong (1986) Downstream transition of river ice jams. Journal of Hydraulics Engineering, ASCE, 112(2): 91-110.

Connor, J.J., and C.A. Brebbia (1978) Finite Element Techniques for Fluid Flow. Butterworth, Inc.

Daly, S.F., and K.D. Axelson (1990) Stability of floating and submerged blocks. IAHR Journal of Hydraulic Research, 28(6): 737-752.

Flato, G., and R. Gerard (1986) Calculation of ice jam thickness profile. Journal of Hydraulic Research, 28(6): 737-752.

Gingold, R.A., and J.J. Monaghan (1977) Smoothed particle hydrodynamics: Theory and application to nonspherical stars. Mon. Not. R. Astr. Soc., 181: 375-389. Gutfraind R., and S.B. Savage (1997) Marginal ice zone rheology: Comparison of results from continuumplastic models and discrete-particle simulations. Journal of Geophysical Research, 102(6): 12,647-12,661.

Hibler, W.D. (1979) A dynamic thermodynamic sea ice model. Journal of Physical Oceanography, 9(4): 815846.

Kawai T., F. Hara, S. Masaki, A. Nishihata, and H. Saeki (1997) Experimental study on the process of ice jam development. In 9th Workshop on River Ice, pp. 245-256.

Lal, A.M.W., and H.T. Shen (1991) A numerical method for simulating dynamic river ice transport. Department of Civil and Environmental Engineering, Clarkson University, Report No. 91-12.

Larsen, P. (1975) Notes on stability of floating ice blocks. In Third IAHR Symposium on Ice Problems, Hanover, New Hampshire.

Latyshenkov, A.M. (1946) A study of protective booms. Gidrotechnicheskiye Stroitel'stro (in Russian), 15(4): 13.

Lu, S., H.T. Shen, and R.D. Crissman (1999) Numerical study of ice jam dynamics in Upper Niagara River. Journal of Cold Regions Engineering, ASCE, 13(2): 78-102.

Lucy, L.B. (1977) A numerical approach to the testing of the fission hypothesis. The Astronomical Journal, 82(12): 1013-1024.

Pariset, E., and R. Hausser (1961) Formation and evolution of ice covers on rivers. Engineering Institute of Canada, Transactions, 5(1): 41-49.

Pariset, E., R. Hausser, and A. Gagnon (1966) 
Formation of ice cover and ice jams in rivers. Journal of Hydraulics Division, ASCE, 92(HY6): 1-24.

Shen, H.T., and Y.C. Chen (1992) Lagrangian discrete parcel simulation of two dimensional river ice dynamics. Department of Civil and Environmental Engineering, Clarkson University, Report No. 92-9.

Shen, H.T., H.H. Shen, and, S.M. Tsai (1990) Dynamic transport of river ice. Journal of Hydraulic Research, 28(9): 659-671.

Shen, H.T., Y.C. Chen, A. Wake, and R.D. Crissman (1993) Lagrangian discrete parcel simulation of river ice dynamics. International Journal of Offshore and Polar Engineering, 3(4): 328-332.

Shen, H.T., S.-A. Lu, and R.D. Crissman (1997) Numerical simulation of ice transport over the Lake Erie-Niagara River ice boom. Cold Regions Science and Technology, 26: 17-33.

Su, J.-S. (1997) River ice dynamic simulation with smoothed particle hydrodynamics. Ph.D. Dissertation, Department of Civil and Environmental, Engineering Clarkson University.

Tatinclaux, J.-C., and M. Gogus (1981) Stability of floes below a floating cover. In Proceedings, International Symposium on Ice, Quebec, vol. 1.

Tuthill, A.M. (1995) Structural ice control—review of existing methods. U.S. Army Cold Regions Research and Engineering Laboratory, Special Report 95-18.

Tuthill, A.M., and G. Gooch (1998) A physical model study of ice retention booms. In Proceedings, 14th IAHR
International Symposium on Ice, Potsdam, New York, pp. 61-68.

Tuthill, A.M., and A.C. Mamone (1998) Structural ice control alternatives for Middle Mississippi River. ASCE Journal of Cold Regions Engineering, 12(4): 202-220.

Uzuner, M.S. (1977) Stability analysis of floating and submerged ice floes. Journal of Hydraulics Division, ASCE, 103(HY12): 713-722.

Uzuner, M.S., and J.F. Kennedy (1976) Theoretical model of river ice jam. Journal of Hydraulics Division, ASCE, 102(HY9): 1365-1383.

Wake, A., and R.R. Rumer (1983) Great Lakes ice dynamics simulation. Journal of Waterways, Port, Coastal and Ocean Engineering, ASCE, 109(1): 86-102.

Wake, A., and Q. Xiao (1989) Upper Niagara River ice dynamics simulation, Phase I: Hydrodynamic simulation of the grass island pool. Report submitted to New York Power Authority and Ontario Hydro.

White K.D. (1992) Salmon River experimental ice boom, 1989-90 and 1990-91 winter seasons. U.S. Army Cold Regions Research and Engineering Laboratory, Special Report 92-20.

Wu, J. (1973) Prediction of near-surface drift currents from wind velocity. Journal of Hydraulics Division, ASCE, 99.

Zufelt, J.E., and R. Ettema (1997) Unsteady ice jam processes. U.S. Army Cold Regions Research and Engineering Laboratory, CRREL Report 97-7. 


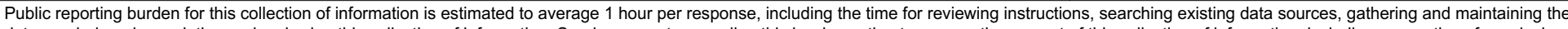

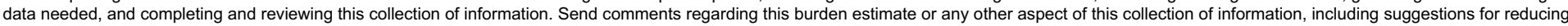

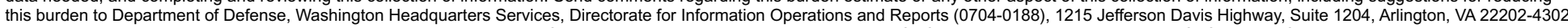

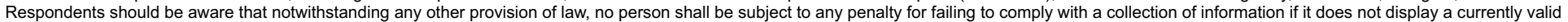
OMB control number. PLEASE DO NOT RETURN YOUR FORM TO THE ABOVE ADDRESS.
1. REPORT DATE (DD-MM-YY)
2. REPORT TYPE
August 2000
Technical Report
3. DATES COVERED (From - To)

4. TITLE AND SUBTITLE

5a. CONTRACT NUMBER

Numerical Simulation of

5b. GRANT NUMBER

River Ice Control with Booms

5c. PROGRAM ELEMENT NUMBER

6. AUTHOR(S)

5d. PROJECT NUMBER

Lianu Liu and Hung Tao Shen

5e. TASK NUMBER

5f. WORK UNIT NUMBER

7. PERFORMING ORGANIZATION NAME(S) AND ADDRESS(ES)

8. PERFORMING ORGANIZATION REPORT NUMBER

U.S. Army Engineer Research and Development Center

Cold Regions Research and Engineering Laboratory

72 Lyme Road

ERDC/CRREL TR-00-10

Hanover, New Hampshire 03755-1290

9. SPONSORING/MONITORING AGENCY NAME(S) AND ADDRESS(ES)

10. SPONSOR / MONITOR'S ACRONYM(S)

11. SPONSOR / MONITOR'S REPORT

NUMBER(S)

\section{DISTRIBUTION / AVAILABILITY STATEMENT}

Approved for public release; distribution is unlimited.

Available from NTIS, Springfield, Virginia 22161.

13. SUPPLEMENTARY NOTES

\section{ABSTRACT}

In this study a two-dimensional numerical model for simulating ice transport and accumulation in the vicinity of river ice booms is developed. The model considers the dynamics of surface ice transport in the river, coupled with the hydrodynamics of the flow. The water flow inside the moving surface ice and the ice accumulation is included in the hydrodynamics. The Lagrangian discrete-parcel method with smoothed particle hydrodynamics is used to simulate the ice dynamics and a finite-element method is used to solve the hydrodynamic equations. Ice entrainment at the boom or the leading edge and underside of the ice accumulation, as well as the limiting boom load for ice retention, are considered. The model is verified with analytical solutions for idealized ice jams in a rectangular channel, and calibrated to an ice jam that progressed up the lower Missouri River during January 1977. The model is then used to assess the feasibility of ice booms on the lower Missouri River. The results show that conventional ice booms may not be effective for typical flow conditions in the lower Missouri River, unless the water level at the Missouri-Mississippi River confluence is high and the water discharge is low.

15. SUBJECT TERMS

Ice booms

Ice jams

16. SECURITY CLASSIFICATION OF:

a. REPORT

$\mathrm{U}$ b. ABSTRACT

U

U
Mississippi River

Missouri River

17. LIMITATION OF OF ABSTRACT

$\mathrm{U}$
River ice

Simulation modeling

18. NUMBER OF PAGES

38 19a. NAME OF RESPONSIBLE PERSON

19b. TELEPHONE NUMBER (include area code) 